\title{
Diatomeas potencialmente nocivas del Golfo San Matías (Argentina)
}

\author{
Potentially harmful diatoms from the San Matías Gulf(Argentina) \\ Inés Sunesen ${ }^{1}$, Alejandra Bárcena ${ }^{1}$ y Eugenia A. Sar ${ }^{1,2}$ \\ ${ }^{1}$ Departamento Científico Ficología, Facultad de Ciencias Naturales y Museo, Universidad Nacional de La Plata \\ Paseo del Bosque s/n, 1900 La Plata, Argentina \\ ${ }^{2}$ Consejo Nacional de Investigaciones Científicas y Técnicas (CONICET), Argentina \\ easar@museo.fcnym.unlp.edu.ar
}

\begin{abstract}
Diatoms responsible for harmful events in other geographic areas, found in the coastal waters of the San Matías Gulf (Río Negro Province, Argentina), were studied. Materials were collected in two sampling stations related to natural banks and cultures of bivalves: Las Grutas and Piedras Coloradas. Two potentially toxigenic taxa and 18 harmful non toxigenic taxa were found. Despite that some of these taxa were occasionally abundant in the plankton of the area, none of them caused evident discolorations or detectable harmful effects during the study period.
\end{abstract}

Key words: Diatoms, harmful, toxigenic, not toxigenic

\section{Introducción}

Las diatomeas, así como otros organismos, son capaces de producir proliferaciones masivas, relativamente repentinas y espacialmente restringidas de una o unas pocas especies. A estos fenómenos se los conoce como floración ('bloom'), marea roja, discoloraciones o alocoloraciones. En cambio, se denomina 'harmful algal blooms (HAB) o floraciones algales nocivas (FAN)' a aquellos eventos capaces de producir niveles de toxinas en moluscos que ponen en riesgo la salud humana, aún con concentraciones celulares moderadas que no llegan a provocar discoloraciones evidentes a ojo desnudo (Reguera 2002) o a todos los eventos perjudiciales desde el punto de vista antropocéntrico, sean toxígenos o no toxígenos (Zingone \& Wyatt 2004).

Once especies pertenecientes al género Pseudonitzschia H. Peragallo, Amphora coffeaeformis (Agardh) Kützing y Nitzschia navis-varingica Lundholm \& Moestrup han sido reportadas como nocivas toxígenas (Bates et al. 1989, Martin et al. 1990, Buck et al. 1992, Smith et al. 1991, Lundholm et al. 1994, Rhodes et al. 1996, 1998, Shimizu et al. 1989, Maranda et al. 1990, Kotaki et al. 2000, Lundholm \& Moestrup 2000, Lundholm et al. 2003, Fryxell \& Hasle 2004, Cerino et
Resumen.- Este trabajo tuvo como objetivo estudiar las diatomeas presentes en las aguas costeras del área norte del Golfo San Matías (Provincia de Río Negro, Argentina) que han sido citadas como productoras de eventos nocivos en otras áreas geográficas. El material fue recolectado en dos estaciones de muestreo: Las Grutas y Piedras Coloradas, relacionadas con bancos naturales y cultivo de bivalvos respectivamente. Dos taxa potencialmente toxígenos y 18 taxa nocivos no toxígenos fueron hallados. A pesar de que algunos de ellos fueron ocasionalmente abundantes en el plancton del área, ninguno produjo discoloraciones evidentes ni se detectó que hubieran causado efectos nocivos durante el período de estudio.

Palabras clave: Diatomeas, nocivas, toxígenas, no toxígenas

al. 2004, Bill et al. 2005' $)$. La toxina que producen es el ácido domoico (AD) que puede causar intoxicaciones humanas y ha sido reportada como causal de muerte de personas, mamíferos y aves marinas (ver revisión en Bates 2000), y el vector más común son los moluscos filtradores que tienen la capacidad de acumularla. El AD se denomina también Veneno Amnésico de Moluscos (VAM) (Todd 1990), dado que produce un síndrome caracterizado por pérdida de la memoria de corto plazo. Las especies toxígenas de los géneros Pseudo-nitzschia y Amphora presentes en aguas costeras del litoral marítimo argentino fueron objeto de varios estudios ultraestructurales previos (Sar et al. 1998, Ferrario et al. 1999, Sala et al. 1998, Ferrario et al. 2002, Sar et al. 2006).

Otro grupo de especies pertenecientes a los géneros Coscinodiscus Ehrenberg, Thalassiosira Cleve, Cerataulina H. Peragallo ex Schütt, Proboscia Sundström, Pseudosolenia Sundström, Rhizosolenia Brightwell, Chaetoceros Ehrenberg, Ceratoneis

\footnotetext{
${ }^{1}$ Bill BD, N Lundholm, L Connell, KA Baugh \& V Trainor. 2005. Domoid acid in Pseudo-nitzschia cuspidata from Washington State coastal waters. $3^{\text {rd }}$ Symposium on Harmful Algae in the US, Monterey, CA. Oct. 2-7, (Abstract), p. 77.
} 
Ehrenberg, Guinardia H. Peragallo, Leptocylindrus Cleve, Asterionellopsis Round, Tabularia (Kützing) Williams \& Round, Minutocellulus Hasle, von Stosch \& Syvertsen, Skeletonema Greville y Pseudohimantidium Hustedt \& Krasske, aparecen en la literatura como productoras de eventos nocivos no toxígenos (ZavalaCamin \& Yamanaka 1980, Clément \& Lembeye 1993, Hallegraeff 2004, Hasle \& Fryxell 1995, Andersen et al. 1995, Hargraves \& Maranda 2002, Fryxell \& Hasle 2004, Smayda 2006). Estas especies pueden causar muerte indiscriminada de peces e invertebrados por agotamiento de oxígeno, afectar la migración de peces por producción de compuestos ricos en proteínas, dañar las branquias de peces mecánicamente o provocar perjuicios a las actividades turísticas y recreativas en áreas costeras por formación de espumas, sustancias aceitosas, manchas u olores. Estudios ultraestructurales de algunas especies nocivas no toxígenas presentes en aguas costeras del litoral marítimo argentino, pertenecientes a varios de los géneros citados precedentemente, fueron publicadas por Sar et al. (2001, 2002), Sunesen \& Sar (2004, 2007a, b), Sunesen (2007) y Sunesen et al. (2008).

En el área norte del Golfo San Matías donde hay bancos naturales de moluscos y se realizan cultivos de mejillón a escala comercial, han sido realizados estudios previos que permitieron detectar varias de las especies citadas como nocivas no toxígenas y algunas de las especies que son potencialmente toxígenas. Sobre la base de esta evidencia y de cara a la preservación de la salud pública, al manejo de los cultivos de moluscos y a la colocación de los productos de acuicultura en los mercados más exigentes, planteamos un proyecto de monitoreo de especies nocivas, su aislamiento y cultivo para estudio morfológico y toxicológico y el monitoreo de toxinas en moluscos. Este trabajo tiene como objetivo presentar, de un modo compendiado, los datos morfológicos y de distribución de las especies y variedades halladas en el área norte del Golfo San Matías que fueron mencionadas en la literatura como causantes de eventos nocivos en otras áreas geográficas.

\section{Material y métodos}

El material estudiado fue recolectado quincenalmente en dos estaciones del área norte del Golfo San Matías: Las Grutas y Piedras Coloradas (Fig. 1), relacionadas con bancos naturales y áreas de cultivo de moluscos bivalvos respectivamente. Las muestras cualitativas fueron tomadas en la capa superficial de la columna de agua, con red de plancton de $30 \mu \mathrm{m}$ de abertura de malla y fijadas con formol al 4\% (concentración final) y las muestras cuantitativas fueron tomadas con botella en la capa sub-superficial entre 1 y $2 \mathrm{~m}$ de la columna de agua y fijadas con formol al $0,4 \%$ (concentración final).

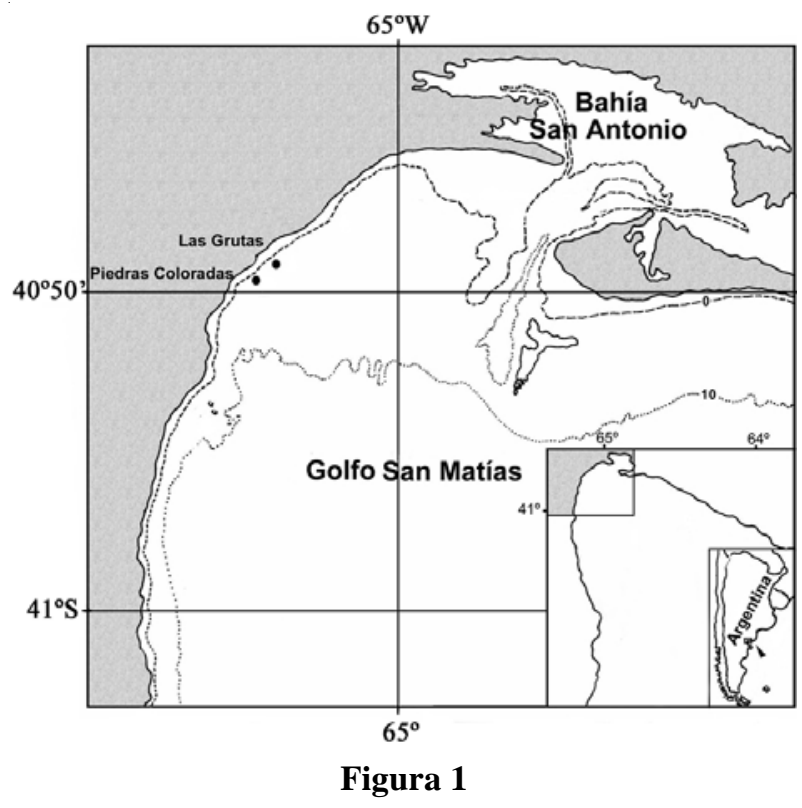

Mapa de la zona norte del Golfo San Matías mostrando las estaciones de muestreo y la localización del área en Argentina

Map of the northern San Matías Gulf showing sampling stations and the location of the area in Argentina

Las muestras cualitativas fueron oxidadas para eliminar la materia orgánica siguiendo los métodos de Hasle \& Fryxell (1970) y Prygiel \& Coste (2000). Los materiales tratados fueron montados para su análisis con microscopio óptico (MO) y microscopio electrónico de barrido (MEB) según los protocolos descriptos por Ferrario et al. (1995). Los preparados permanentes, las muestras tratadas y las muestras sin tratar fueron depositados en la Colección de Diatomeas Argentinas del Departamento Científico Ficología, Facultad de Ciencias Naturales y Museo, UNLP, Argentina, bajo los números 13645 al 13685 (Tabla 1).

Las muestras cuantitativas fueron analizadas para estimar el número de células por litro con cámara Sedgewick-Rafter sólo en los casos de aquellas especies nocivas toxígenas o no toxígenas que aparecieron abundantes o dominantes en las muestras cualitativas.

Las observaciones fueron hechas con microscopios ópticos Wild M20 y Nikon Microphot-FX bajo contraste de fase. Las fotomicrografías fueron obtenidas usando este último microscopio óptico y microscopio electrónico de barrido Jeol JSM 6360 LV.

La terminología general utilizada es la recomendada por Ross et al. (1979), Round et al. (1990) y Nikolaiev (1993) y la terminología particular para los géneros tratados Sundström (1986), Rines \& Hargraves (1988), 


\section{Tabla 1}

Estaciones de muestreo, fechas de colecta y número con que fueron depositadas las muestras en la Colección de Diatomeas Argentinas. $\quad P C=$ Piedras Coloradas y LG = Las Grutas

Key to sampling stations dates of collection and sample numbers at the Colección de Diatomeas Argentinas. $\mathrm{PC}=$ Piedras Coloradas and $\mathrm{LG}=$ Las Grutas

\begin{tabular}{lcclcc}
\hline \multicolumn{1}{c}{ Fecha } & PC & LG & \multicolumn{1}{c}{ Fecha } & PC & LG \\
\hline Marzo 2006 & 13645 & & Julio 2006 & & 13668 \\
Marzo 2006 & 13649 & 13650 & Julio 2006 & 13669 & 13670 \\
Abril 2006 & 13652 & 13651 & Agost. 2006 & 13671 & 13672 \\
Abril 2006 & 13655 & 13656 & Sept. 2006 & 13674 & 13675 \\
Mayo 2006 & 13657 & 13658 & Sept. 2006 & 13677 & 13676 \\
Mayo 2006 & 13654 & 13653 & Nov. 2006 & 13679 & 13678 \\
Mayo 2006 & 13664 & 13665 & Febr. 2007 & 13681 & \\
Junio 2006 & & 13666 & Febr. 2007 & 13683 & 13682 \\
Junio 2006 & 13667 & & Abril 2007 & 13685 & 13684 \\
\hline
\end{tabular}

Hasle \& Syvertsen (1996), Hernández-Becerril (1996) y Jensen \& Moestrup (1998). El esquema clasificatorio seguido es el de Hasle \& Syvertsen (1996).

\section{Resultados}

Dos especies nocivas toxígenas fueron encontradas: Pseudo-nitzschia australis Frenguelli y Pseudo-nitzschia pungens (Grunow ex P.T. Cleve) Hasle. Asimismo, 18 taxa nocivos no toxígenos fueron hallados: Cerataulina pelagica (Cleve) Hendey, Ceratoneis closterium Ehrenberg, Coscinodiscus wailesii Gran \& Angst, Chaetoceros danicus Cleve, Ch. debilis Cleve, Ch. lorenzianus Grunow, Ch. socialis Lauder, Guinardia delicatula (Cleve) Hasle, Leptocylindrus danicus Cleve, L. minimus Gran, Pseudosolenia calcar-avis (Schultze) Sundström, Rhizosolenia setigera Brightwell f. setigera, $R$. setigera f. pungens (Cleve-Euler) Brunel, Thalassiosira anguste-lineata (Schmidt) Fryxell \& Hasle, T. fryxelliae Sar \& Sunesen, T. mala Takano, T. rotula Meunier y T. simonsenii Hasle \& Fryxell.

Dado que estos taxa fueron previamente estudiados para aguas costeras de Argentina se señala la literatura relevante usada para su identificación y en cada caso aquella en que se reporta como nocivo, se presentan los datos morfométricos del material analizado, se puntualizan los caracteres diagnósticos y se provee información sobre su distribución en Argentina e ilustraciones con MO y MEB.

\section{Orden Bacillariales}

Familia Bacillariaceae Ehrenberg

Pseudo-nitzschia australis Frenguelli (Fig. 2 A-E)

Caracteres distintivos: Colonias en escalera formadas por superposición de los extremos valvares en aproximadamente $1 / 4$ del largo total de las células. Frústulos linear-lanceolados con ápices agudos en vista cingular. Valva lanceolada, ancha, con lados paralelos en
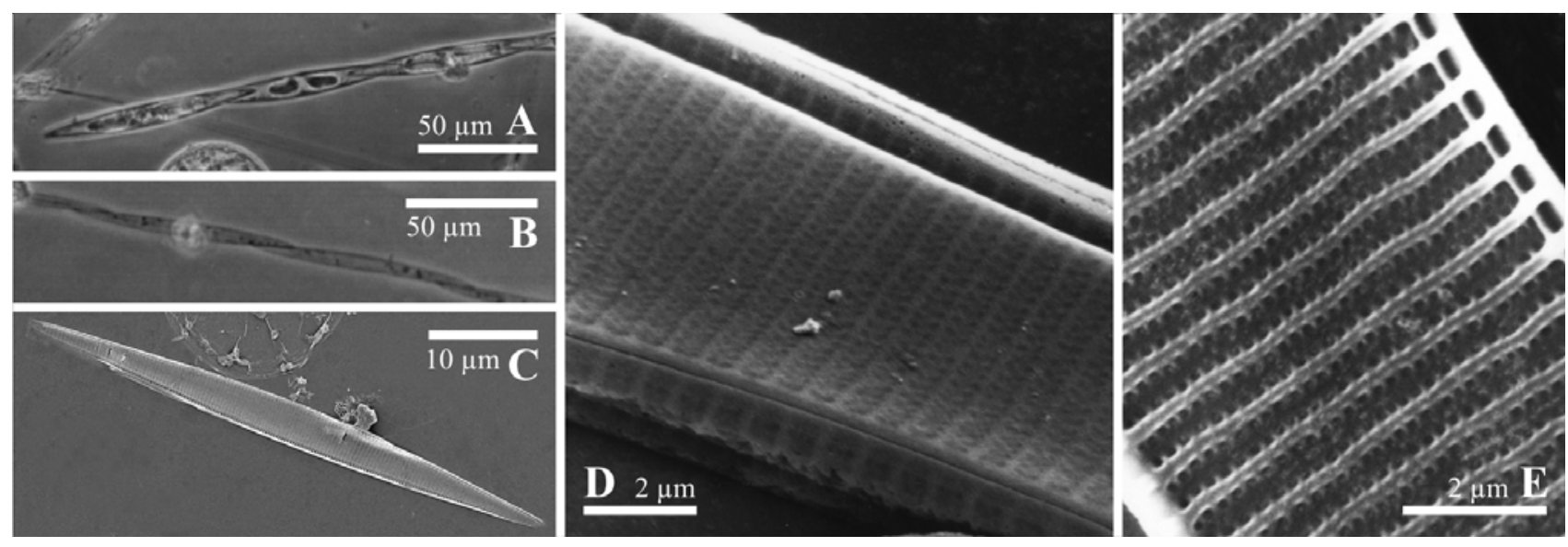

Figura 2

Pseudo-nitzschia australis. A-B, Microscopia óptica (MO). C-E, Microscopía electrónica de barrido (MEB). A. Cadena en vista valvar. B. Cadena en vista cingular. C. Valva en vista externa. D. Parte central de la valva en vista externa. E. Parte central de la valva en vista interna

Pseudo-nitzschia australis. A-B, Light microscopy (LM). C-E, Scanning electron microscopy (SEM). A. Chain in valvar view. B. Chain in girdle view. C. Valve in external view. D. Central part of the valve in external view. E. Central part of the valve in internal view 
su parte media o ligeramente asimétricas respecto del eje apical. Extremos valvares subrostrados. Superficie valvar con estrías formadas por dos hileras de poroides circulares e interestrías internamente elevadas que coinciden en número con las fíbulas. Rafe excéntrico, sin interespacio central.

Parámetros morfométricos: eje apical 73,6-116 $\mu \mathrm{m}$; eje transapical 6,4-8 $\mu \mathrm{m}$; fíbulas $15-16$ en $10 \mu \mathrm{m}$; interestrías 13-16 en $10 \mu \mathrm{m}$; poroides en la estría 4-5 en $1 \mu \mathrm{m}$.

Referencias: Frenguelli (1939a), Villac et al. (1993), Hasle et al. (1996), Ferrario et al. (1999).

Distribución para Argentina: Pseudo-nitzschia australis es una especie cosmopolita según Hasle (2002) que fue descripta sobre la base de material colectado en el Golfo San Matías por Frenguelli (1939a). Esta especie fue reportada bajo el nombre de Nitzschia pseudoseriata Hasle por Hasle (1965) para Puerto Quequén y el área norte del Golfo San Matías y por Lange (1985) para aguas de la Plataforma del Mar Argentino entre $38^{\circ} 12^{\prime} \mathrm{S}$, $57^{\circ} 15^{\prime} \mathrm{W}$ y $39^{\circ} 59^{\prime} \mathrm{S}, 54^{\circ} 11^{\prime} \mathrm{W}$. Negri \& Inza (1998) la citaron para aguas de la Plataforma del Mar Argentino frente a Mar del Plata, Ferrario et al. $(1999,2002)$ para aguas costeras de la Provincia de Buenos Aires y Las Grutas en el Golfo San Matías, Sastre et al. (2001) para los Golfos San Matías y Nuevo, y Almandoz et al. (2007) para aguas de plataforma del Mar Argentino entre los $35^{\circ} \mathrm{S}$ y $54^{\circ} \mathrm{S}$.

En el presente estudio, P. australis fue encontrada en las muestras cualitativas de ambas estaciones de muestreo, rara a abundante en otoño e invierno. La concentración máxima alcanzada por la especie en las muestras cuantitativas correspondientes fue de $2,2 \cdot 10^{3}$ cél $\mathrm{L}^{-1}$.

Datos sobre producción de toxinas en otras áreas geográficas: Pseudo-nitzschia australis fue reportada por primera vez en 1991 como productora de ácido domoico en la Bahía de Monterrey, California, en oportunidad de que produjera una mortandad masiva de aves marinas (Garrison et al. 1992, Buck et al. 1992, Fritz et al. 1992). Ulteriormente la especie fue reportada como causante de intoxicaciones leves en humanos en Los Ángeles, Oregon y boca del Río Columbia (Anonymous 1991), de vedas al consumo de bivalvos (Anonymous 1991), y de mortalidad masiva de leones marinos en Bahía Monterrey, California (Scholin et al. 2000).

Negri et al. (2004) describieron el primer registro de ácido domoico, que fue producido por $P$. australis, para la plataforma continental argentina frente a Mar del Plata, en muestras de fitoplancton, de mejillones (Mytilus edulis) y de anchoíta (Engraulis anchoita).
Pseudo-nitzschia pungens (Grunow ex P.T. Cleve) Hasle (Fig. 3 A-F)

Caracteres distintivos: Colonias en escalera formadas por superposición de los extremos valvares en aproximadamente $1 / 3$ del largo total de las células. Frústulos fusiformes con ápices agudos en vista cingular. Valva linear, angosta, con lados paralelos en su parte media, a fusiforme en los especímenes pequeños, con ápices agudos. Superficie valvar con estrías formadas por dos hileras de poroides circulares e interestrías internamente elevadas que coinciden en número con las fíbulas. Rafe excéntrico, sin interespacio central.

Parámetros morfométricos: eje apical 73-95 $\mu \mathrm{m}$; eje transapical 2,2-3,9 $\mu \mathrm{m}$; fíbulas 9-16 en $10 \mu \mathrm{m}$; interestrías 9-14 en $10 \mu \mathrm{m}$; poroides en la estría 3-4 en $1 \mu \mathrm{m}$.

Referencias: Hasle et al. (1996), Ferrario et al. (1999).

Distribución para Argentina: Pseudo-nitzschia pungens es una especie cosmopolita según Hasle (2002), que fue reportada por Lange (1985) bajo el nombre de Nitzschia pungens Grunow ex P. T. Cleve, para aguas de la plataforma del Mar Argentino entre $38^{\circ} 12^{\prime} \mathrm{S}, 57^{\circ} 15^{\prime} \mathrm{W}$ y $39^{\circ} 59^{\prime} \mathrm{S}, 54^{\circ} 11^{\prime} \mathrm{W}$. Negri \& Inza (1998) la citaron para aguas de la Plataforma del Mar Argentino frente a Mar del Plata, Ferrario et al. (1999) para aguas costeras de la Provincia de Buenos Aires, Sastre et al. (2001) para los Golfo San Matías, San José y Nuevo, y Almandoz et al. (2007) para aguas de plataforma del Mar Argentino entre $\operatorname{los} 35^{\circ} \mathrm{S}$ y $54^{\circ} \mathrm{S}$.

En el presente estudio $P$. pungens fue encontrada en las muestras cualitativas de ambas estaciones de muestreo, escasa a abundante en otoño e invierno. Adicionalmente, en Piedras Coloradas, fue hallada escasa en verano. La concentración máxima alcanzada por la especie en las muestras cuantitativas correspondientes fue de $3,4 \cdot 10^{3}$ cél $\mathrm{L}^{-1}$.

Datos sobre producción de toxinas en otras áreas geográficas: Pseudo-nitzschia pungens se reportó por primera vez como productora de ácido domoico a partir del análisis de cepas aisladas en Nueva Zelanda (Rhodes et al. 1996) y nunca fue reportada como causante de intoxicaciones en humanos.

\section{Ceratoneis closterium Ehrenberg (Fig. 4 A-B)}

Caracteres distintivos: Células solitarias o formando grandes agregados. Frústulos fusiformes, débilmente silicificados, con extremos alargados, rostrados y girados sobre su eje apical. Superficie valvar con escasas perforaciones y con engrosamientos transapicales más o menos silicificados. Rafe atravesado por una serie de fíbulas. 

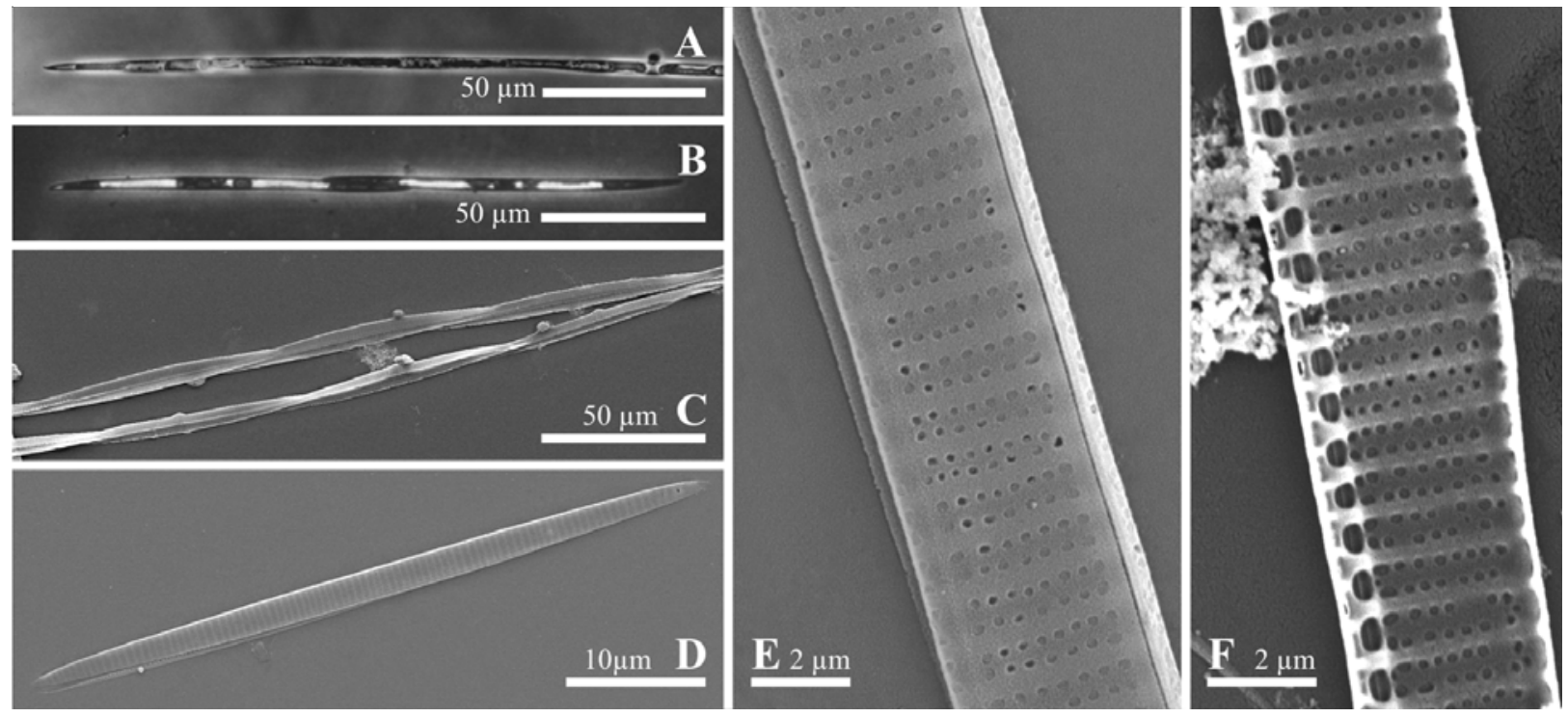

Figura 3

Pseudo-nitzschia pungens. A-B, MO. C-F, MEB. A. Cadena en vista valvar. B. Cadena en vista cingular. C. Cadena en vista cingular inclinada. D. Valva en vista externa. E. Parte central de la valva en vista externa. F. Parte central de la valva en vista interna

Pseudo-nitzschia pungens. A-B, LM. C-F, SEM. A. Chain in valvar view. B. Chain in girdle view. C. Chain in tilted, girdle view. D. Valve in external view. E. Central part of the valve in external view. F. Central part of the valve in internal view

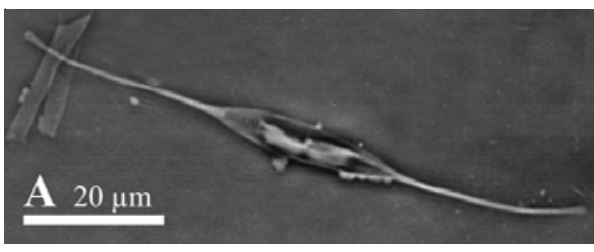

Ceratoneis closterium. A, MO. B, MEB. A. Aspecto general de la célula. B. Célula mostrando bandas de la cintura

Ceratoneis closterium. A, LM. B, SEM. A. General aspect of the cell. B. Cell showing girdle bands

Parámetros morfométricos: eje apical 29-139 $\mu \mathrm{m}$; eje transapical 2-4 $(6,5) \mu \mathrm{m}$.

Referencias: Jahn \& Kusber (2005), Sunesen \& Sar (2007b).

Distribución para Argentina: Ceratoneis closterium, especie probablemente cosmopolita, planctónica y común sobre macroalgas y hielos polares (Hasle \& Syvertsen 1996), ha sido frecuentemente reportada para aguas del mar Argentino bajo el nombre Cylindrotheca closterium (ver Ferrario \& Galván 1989 y Vouilloud 2003). Recientemente fue citada para aguas costeras de la Provincia de Buenos Aires por Sunesen \& Sar (2007b).
Durante el presente estudio, C. closterium fue encontrada en ambas estaciones de muestreo, escasa a lo largo de todo el año.

Asociación a eventos nocivos en otras áreas geográficas: Ceratoneis closterium $\equiv$ Cylindrotheca closterium, ha sido asociada a eventos nocivos producidos en aguas costeras del Mar Adriático, Italia. El fenómeno localmente conocido como 'mare sporco' y reportado desde 1723 hasta el presente, en el verano de 1988 se produjo en tal extensión que afectó el turismo y las pesquerías (Hasle \& Fryxell 1995). Alcoverro et al. (2000) determinaron que C. closterium era la responsable de la producción de los grandes agregados mucilaginosos y de la formación de la 'nieve marina' en aguas costeras del Mar Adriático. 

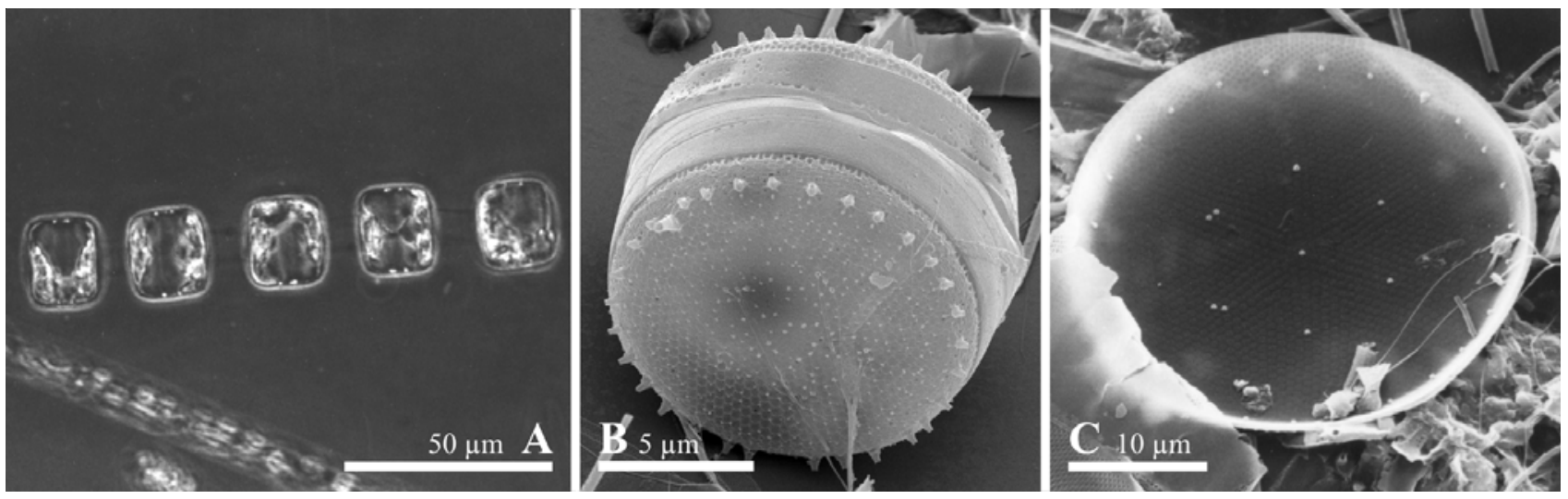

Figura 5

Thalassiosira anguste-lineata. A, MO. B-C, MEB. A. Cadena de células unidas por varios tractos mucilaginosos. B. Frústulo mostrando valva y cintura. C. Valva en vista interna

Thalassiosira anguste-lineata. A, LM. B-C, SEM. A. Chain of cells united by several connecting mucilage threads. B. Frustule showing valve and girdle. C. Valve in internal view

\section{Orden Biddulphiales}

Familia Thalassiosiraceae Lebour emend. Hasle

Thalassiosira anguste-lineata (Schmidt) Fryxell \& Hasle (Fig. 5 A-C)

Caracteres distintivos: Células reunidas en colonias por varios tractos mucilaginosos. Patrón de distribución de los procesos reforzados, un anillo marginal completo y un anillo ubicado generalmente en la mitad del radio, discontinuo, conformado por procesos dispuestos en arcos, (1) 2-6 procesos por arco; procesos marginales urceolados. Proceso labiado marginal ubicado en el anillo de procesos reforzados con tubo externo conspicuo.

Parámetros morfométricos: diámetro 16-40 $\mu \mathrm{m}$; areolas en el centro 7-14 en $10 \mu \mathrm{m}$, en el manto $24-28$ en $10 \mu \mathrm{m}$; procesos reforzados marginales 3-5 en $10 \mu \mathrm{m}$; costillas marginales 12 en $10 \mu \mathrm{m}$.

Referencias: Fryxell \& Hasle (1977), Sar et al. (2001), Sunesen (2007).

Distribución para Argentina: Esta especie cosmopolita (Harris et al. 1995), ha sido reportada por numerosos autores para el Mar Argentino (ver Ferrario \& Galván 1989). Más recientemente fue reportada por Gayoso (1988) para el estuario de Bahía Blanca, por Sar (1996) para Bahía San Antonio, por Sar et al. (2001) para aguas costeras de la Provincia de Buenos Aires y por Sar et al. (2002) para aguas costeras del área norte del Golfo San Matías.

Durante el presente estudio, T. anguste-lineata fue encontrada escasa en otoño e invierno en Piedras Coloradas y en invierno en Las Grutas.

Asociación a eventos nocivos en otras áreas geográficas: Thalassiosira anguste-lineata fue mencionada por Koray (2004) como causante de mortalidades masivas de organismos acuáticos debido a las condiciones de hiperoxia y anoxia generadas por sus floraciones en zonas eutróficas de las costas de Turquía.

\section{Thalassiosira fryxelliae Sar \& Sunesen (Fig. 6 A-C)}

Caracteres distintivos: Células embebidas en una masa gelatinosa irregular. Patrón de areolación variable, linear, sublinear, excéntrico o irregular. Ausencia de procesos sobre la superficie valvar. Un anillo marginal de procesos reforzados con tubo externo. Proceso labiado marginal incluido en el anillo de procesos reforzados con tubo externo conspicuo.

Parámetros morfométricos: diámetro 6-23 $\mu \mathrm{m}$; areolas en el centro (11)12-19 (20) en $10 \mu \mathrm{m}$, en el manto 23-30 en $10 \mu \mathrm{m}$; procesos reforzados marginales 4-6 en $10 \mu \mathrm{m}$; costillas marginales 14-19 en $10 \mu \mathrm{m}$.

Referencias: Sunesen \& Sar (2004).

Distribución para Argentina: Thalassiosira fryxelliae fue descripta sobre la base de material colectado en aguas costeras de la Prov. de Buenos Aires y en el área norte del Golfo San Matías por Sunesen \& Sar (2004).

Durante el presente estudio, T. fryxelliae fue encontrada en ambas estaciones de muestreo, escasa durante todo el año. 

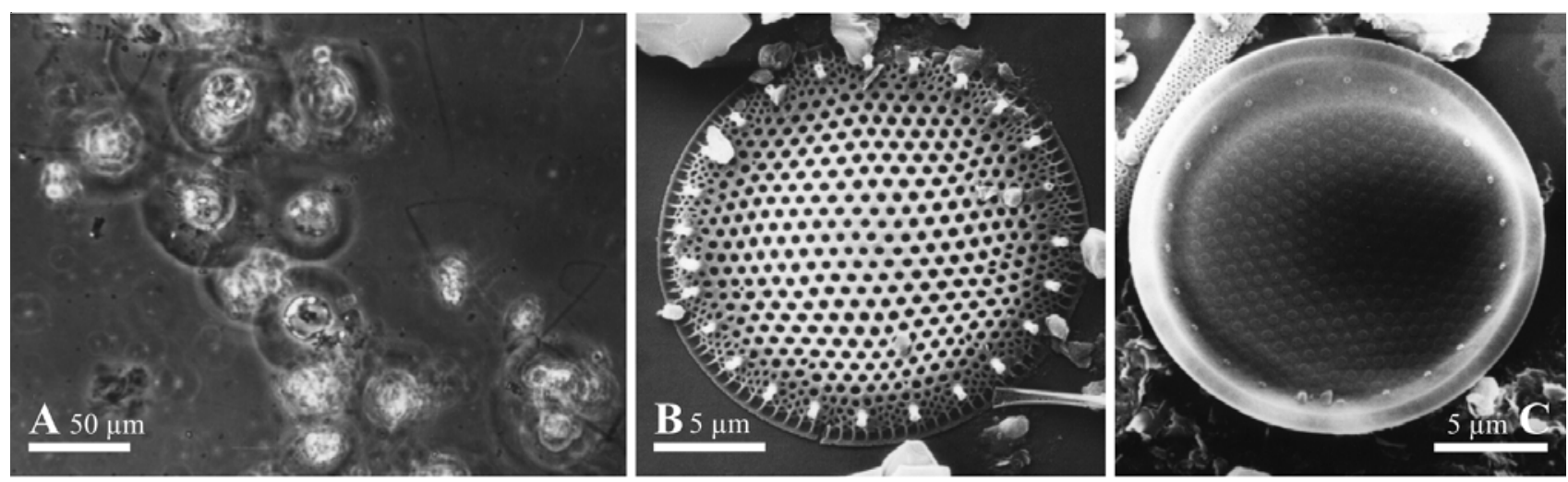

Figura 6

Thalassiosira fryxelliae. A, MO. B-C, MEB. A. Colonia mucilaginosa. B. Valva en vista externa. C. Valva en vista interna

Thalassiosira fryxelliae. A, LM. B-C, SEM. A. Mucilaginous colony. B. Valve in external view. C. Valve in internal view
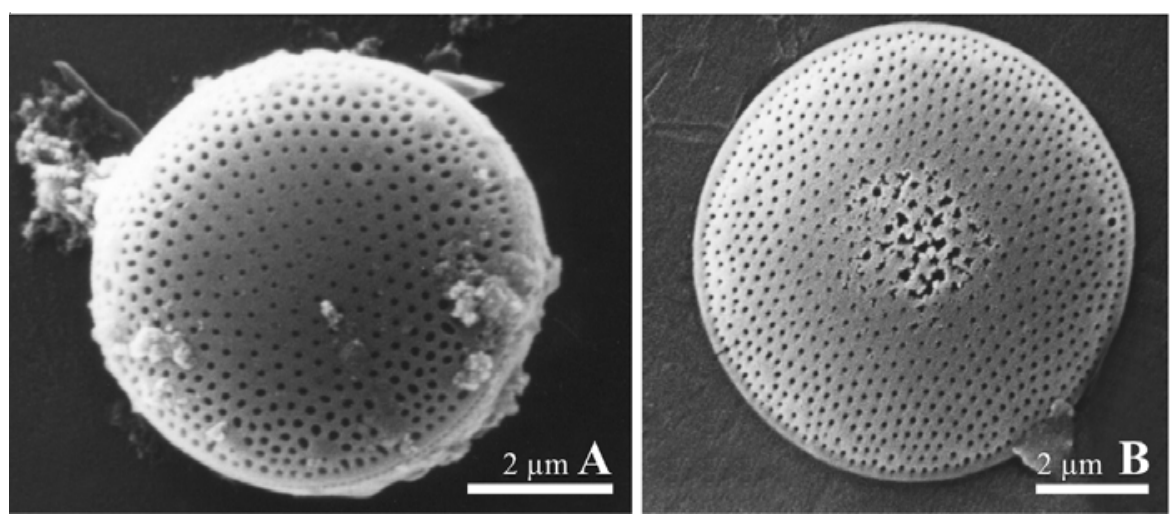

Figura 7

Thalassiosira mala. MEB. A. Frústulo en vista valvar. B. Valva en vista externa.

C. Valva en vista interna

Thalassiosira mala. SEM. A. Frustule in valvar view. B. Valve in external view. C. Valve in internal view

Asociación a eventos nocivos: Thalassiosira fryxelliae es formadora de colonias gelatinosas, como varias otras especies consideradas nocivas o potencialmente nocivas por Hasle \& Fryxell (1995).

\section{Thalassiosira mala Takano (Fig. 7 A-C)}

Caracteres distintivos: Células reunidas en colonias gelatinosas y conectadas por cordones mucilaginosos. Procesos reforzados marginales en un anillo, con tubo interno corto. Proceso reforzado subcentral ubicado cerca del radio que pasa por el proceso labiado marginal. Proceso labiado y procesos reforzados sin tubo externo.
Parámetros morfométricos: diámetro 6-8 $\mu \mathrm{m}$; areolas en el centro 25-35 en $10 \mu \mathrm{m}$, en el manto $40-50$ en $10 \mu \mathrm{m}$; procesos reforzados marginales 10-14 en $10 \mu \mathrm{m}$.

Referencias: Takano (1990), Sar et al. (2002), Sunesen (2007).

Distribución para Argentina: Thalassiosira mala es una especie de aguas cálidas a templadas (Hasle \& Syvertsen, 1996) que fue hallada en aguas costeras del área norte del Golfo San Matías y reportada por primera vez para Argentina por Sar et al. (2002).

En el presente estudio, T. mala fue encontrada en ambas estaciones de muestreo, escasa en otoño e invierno. 

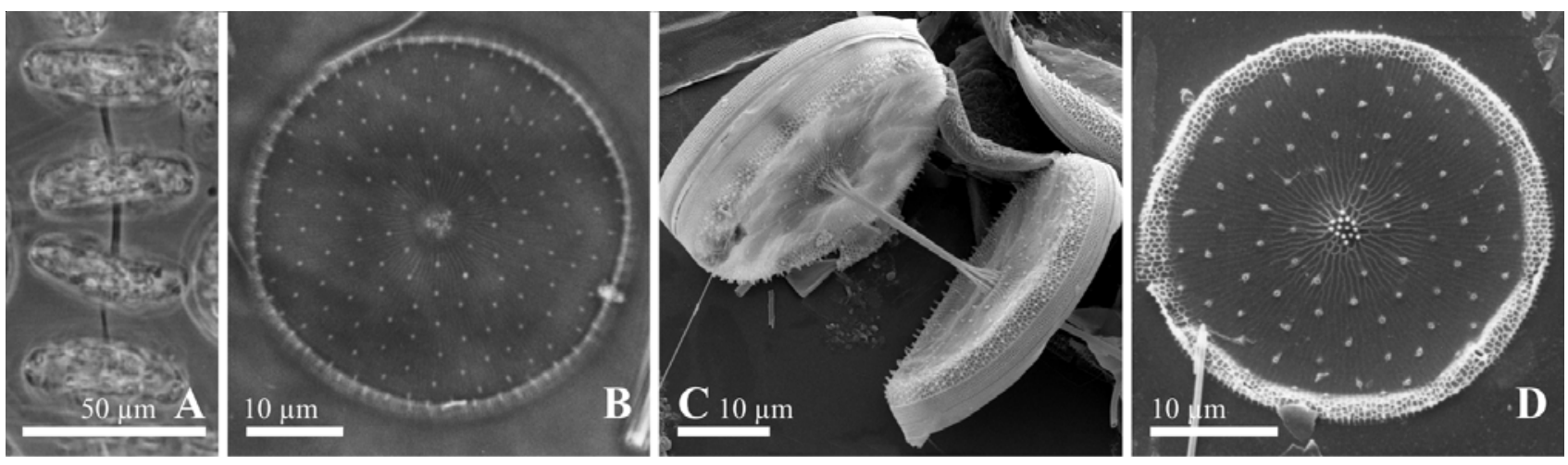

Figura 8

Thalassiosira rotula. A-B, MO. C-D, MEB. A. Cadena de células unidas por un grueso tracto mucilaginoso. B. Valva mostrando distribución de procesos. C. Dos células reunidas por un tracto mucilaginoso. D. Valva en vista externa

Thalassiosira rotula. A-B, LM. C-D, SEM. A. Chain of cells united by a coarse connecting mucilage thread. B. Valve showing processes distribution. C. Two cells united by a coarse connecting mucilage thread. D. Valve in external view

Asociación a eventos nocivos: Thalassiosira mala fue una de las primeras diatomeas marinas planctónicas reportadas como nocivas para bivalvos. Takano (1965) señaló a esta especie como causante de discoloraciones y responsable de grandes pérdidas económicas (de 58 millones de yenes) en áreas de cultivo de moluscos de la Bahía de Tokio en 1951. La especie crece en masas gelatinosas que, durante las floraciones, según Takano (1956) pueden provocar la muerte de bivalvos por taponamiento de branquias.

\section{Thalassiosira rotula Meunier (Fig. 8 A-D)}

Caracteres distintivos: Células reunidas en colonias por un grueso tracto mucilaginoso central. Patrón de areolación con costillas radiales. Procesos reforzados con corto tubo externo dispuestos en un grupo central, esparcidos sobre la superficie valvar y en tres anillos marginales. Un proceso labiado marginal pequeño, con tubo externo, poco conspicuo.

Parámetros morfométricos: diámetro 29-44 (52) $\mu \mathrm{m}$; areolas en el centro $17-18 \frac{1}{2}$ en $10 \mu \mathrm{m}$, en el manto 2937 en $10 \mu \mathrm{m}$; procesos reforzados marginales $12-15$ en $10 \mu \mathrm{m}$; costillas marginales 19-21 en $10 \mu \mathrm{m}$.

Referencias: Sar et al. (2001), Sunesen (2007).

Distribución para Argentina: Thalassiosira rotula es una especie cosmopolita en aguas frío-templadas a cálidas (Hasle 1976), que ha sido reportada para aguas neríticas de Argentina en numerosas ocasiones (ver Ferrario \& Galván 1989, Vouilloud 2003).

Durante el presente estudio, $T$. rotula fue encontrada en ambas estaciones de muestreo, escasa en invierno excepto en una muestra ( $1^{\circ}$ de septiembre) de Piedras Coloradas en la que apareció como dominante. La concentración alcanzada por la especie en la muestra

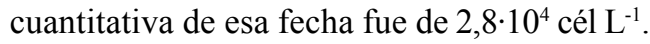

Asociación a eventos nocivos en otras áreas geográficas: Thalassiosira rotula fue mencionada por Koray (2004) como causante de mortalidades masivas de organismos acuáticos debido a las condiciones de hiperoxia y anoxia generadas por sus floraciones en zonas eutróficas de las costas de Turquía.

Thalassiosira simonsenii Hasle \& Fryxell (Fig. 9 A-C)

Caracteres distintivos: Células reunidas en colonias mucilaginosas. Patrón de areolación linear a excéntrico. Un proceso reforzado central pequeño, sin tubo externo. Procesos reforzados en el manto valvar, en un anillo en vista interna, y en dos anillos en vista externa, con tubo externo. Dos procesos labiados ubicados a $180^{\circ}$ con tubo externo robusto y un número variable de procesos ocluidos conspicuos en un anillo situado entre la superficie valvar y el manto. Costillas marginales notorias.

Parámetros morfométricos: diámetro (17) 26-29 $\mu \mathrm{m}$; areolas en el centro (5) $7 \frac{1}{2}-12$ en $10 \mu \mathrm{m}$, en el manto 25 32 en $10 \mu \mathrm{m}$; procesos reforzados marginales 4-6 (8) en $10 \mu \mathrm{m}$; costillas marginales $12-17$ en $10 \mu \mathrm{m}$.

Referencias: Hasle \& Fryxell (1977), Sar et al. (2001), Sunesen (2007).

Distribución para Argentina: Esta especie de aguas cálidas a templadas (Hasle \& Syvertsen 1996) ha sido reportada para aguas de plataforma del Mar Argentino entre los $38^{\circ} 12^{\prime} \mathrm{S}$ y $\operatorname{los} 57^{\circ} 15^{\prime} \mathrm{S}$ por Lange et al. (1983) y Lange 

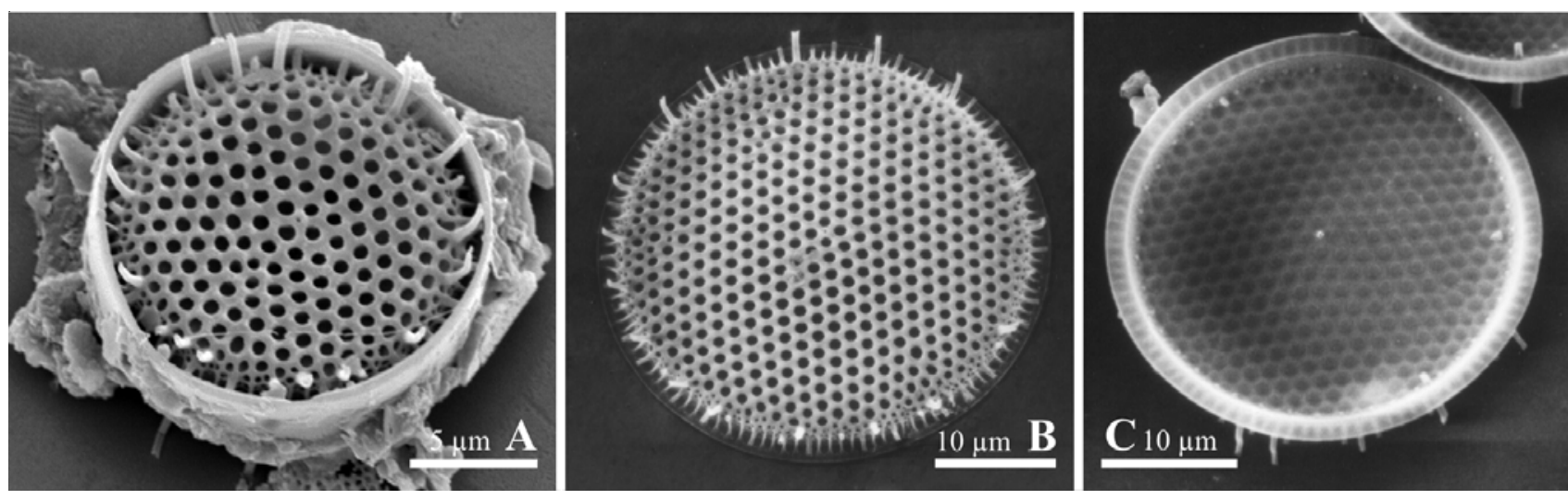

Figura 9

Thalassiosira simonsenii. MEB. A. Frústulo rodeado por mucílago. B. Valva en vista externa. C. Valva en vista interna

Thalassiosira simonsenii. SEM. A. Frustule enveloped in mucilage. B. Valve in external view. C. Valve in internal view

(1985). Ferrario \& Sar (1988) la hallaron para aguas costeras de la Provincia de Chubut y Sar et al. (2001, 2002) para aguas costeras de la Provincia de Buenos Aires y del Golfo San Matías respectivamente.

Durante el presente estudio, T. simonsenii fue encontrada en ambas estaciones de muestreo, escasa en invierno y primavera.

Asociación a eventos nocivos en otras áreas geográficas: Thalassiosira simonsenii es formadora de colonias gelatinosas, como varias otras especies consideradas nocivas o potencialmente nocivas por Hasle \& Fryxell (1995).

\section{Familia Leptocylindraceae Lebour}

Leptocylindrus danicus Cleve (Fig. 10 A-C)

Caracteres distintivos: Células cilíndricas, angostas, alargadas, solitarias o reunidas en cadenas cortas. Numerosos cloroplastos por célula. Valva circular, con la superficie valvar convexa o levemente cóncava y manto redondeado a vertical, con poro subcentral en la adyacencia del annulus inconspicuo o del centro de la valva. Areolas poroides ordenadas en estrías radiales. Anillo de espinas romas en la unión entre la superficie valvar y el manto.

Parámetros morfométricos: diámetro 6-10 $\mu \mathrm{m}$; areolas en el centro 80-100 en $10 \mu \mathrm{m}$, cerca del margen 100-140 en $10 \mu \mathrm{m}$; estrías en el margen $60-75$ en $10 \mu \mathrm{m}$.

Referencias: Takano (1990), Rivera et al. (2002), Sunesen \& Sar (2007b).

Distribución para Argentina: Leptocylindrus danicus es una especie cosmopolita de aguas costeras y de plataforma según Hargraves (1990), probablemente ausente de las áreas antártica y subantártica según Hasle \& Syvertsen (1996). Esta especie ha sido frecuentemente reportada para el Mar Argentino (ver Ferrario \& Galván 1989 y Vouilloud 2003). Más recientemente, Negri et al. (2004) la señalaron para aguas de plataforma frente a Mar del Plata y Sunesen \& Sar (2007b) para aguas costeras del área norte de la Provincia de Buenos Aires.

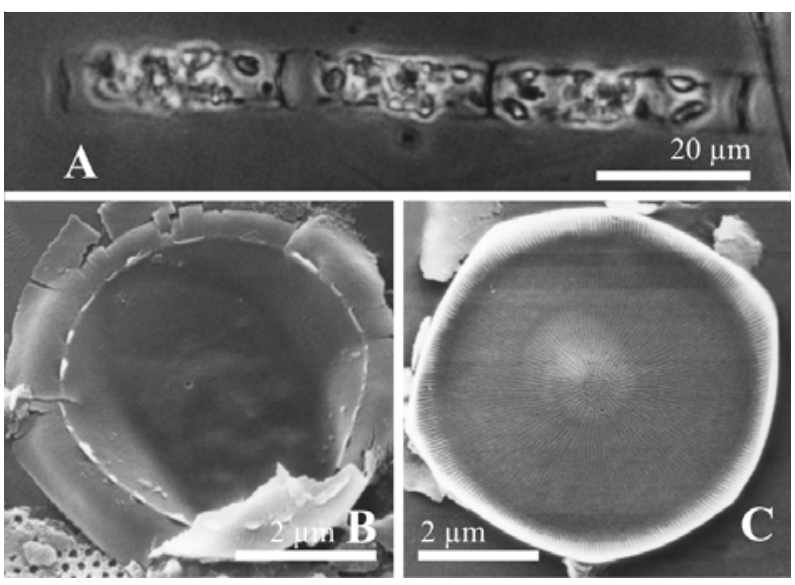

Figura 10

Leptocylindrus danicus. A, MO. B-C, MEB. A. Células reunidas en cadenas. $B$. Vista valvar externa mostrando el anillo de espinas romas y el poro subcentral. $C$. Vista valvar interna

Leptocylindrus danicus. A, LM. B-C, SEM. A. Cells united in chains. B. External valve view showing the marginal ring of flap-like spines and the subcentral pore. C. Internal view of the valve 
En el transcurso del presente estudio, Leptocylindrus danicus ha sido encontrada en Piedras Coloradas, escasa en verano, otoño e invierno.

Asociación a eventos nocivos en otras áreas geográficas: Leptocylindrus danicus ha sido asociada a injurias mecánicas en organismos filtradores del área costera del Estado de Parana, Brasil, por Fryxell \& Villac (1999).

\section{Leptocylindrus minimus Gran (Fig. 11 A-B)}

Caracteres distintivos: Células cilíndricas, muy angostas, alargadas, solitarias o reunidas en cadenas cortas. Dos cloroplastos por célula. Valva circular, con la superficie valvar convexa o levemente cóncava y manto redondeado a vertical, sin poro subcentral en la adyacencia del annulus inconspicuo o del centro de la valva. Areolas poroides ordenadas en estrías radiales.

Parámetros morfométricos: diámetro 1,7-4 $\mu \mathrm{m}$. Las fotos tienen insuficiente detalle para determinar la densidad de estrías y de areolas.

Referencias: Hargraves (1990), Rivera et al. (2002), Sunesen \& Sar (2007b).

Distribución en Argentina: Leptocylindrus minimus es una especie cosmopolita, probablemente ausente de áreas antárticas y subantárticas (Hasle \& Syvertsen 1996) y ha sido reportada en nuestro país para aguas del estuario de Bahía Blanca y del Golfo San Matías (ver Ferrario \& Galván 1989, Vouilloud 2003). Recientemente, Sunesen \& Sar (2007b) la citaron para aguas costeras del área norte de la Provincia de Buenos Aires.
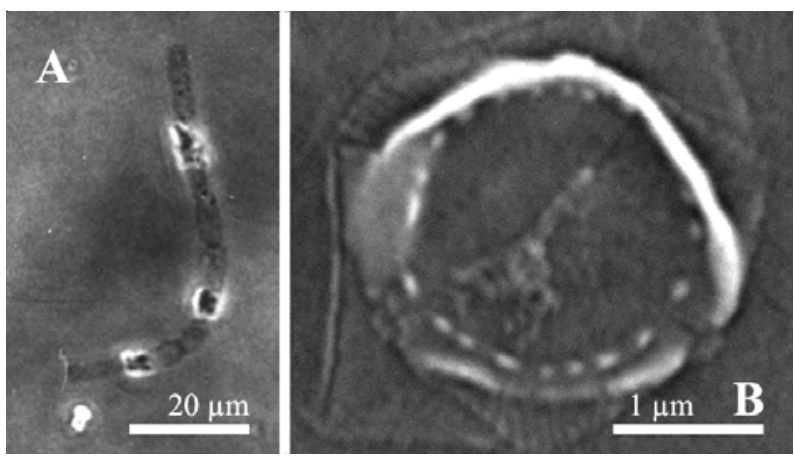

Figura 11

Leptocylindrus minimus. A, MO. B, MEB. A. Células unidas en cadenas. $B$. Vista valvar externa mostrando un anillo marginal de espinas romas

Leptocylindrus minimus. A, LM. B, SEM. A. Cells united in chains. B. Valve in external view showing a marginal ring of flap-like spines
En el presente estudio, L. minimus fue encontrada en Piedras Coloradas, escasa en otoño.

Asociación a eventos nocivos en otras áreas geográficas: Leptocylindrus minimus es una de las especies comúnmente productora de floraciones en aguas costeras y su presencia ha sido asociada a eventos de mortalidad de salmones en cautiverio en los fiordos del sur de Chile (Clément \& Lembeye 1993, Clément 1994, Reguera 2002, Rivera et al. 2002).

\section{Familia Coscinodiscaceae Kützing}

Coscinodiscus wailesii Gran \& Angst (Fig. 12 A-F)

Caracteres distintivos: Frústulos cilíndricos con eje pervalvar alto; valvas planas con manto alto perpendicular a la superficie valvar; dos anillos de procesos, uno en la unión superficie valvar-manto y otro marginal que incluye a los dos procesos macrolabiados, procesos esparcidos al inicio de estrías incompletas.

Parámetros morfométricos: diámetro $128-300 \mu \mathrm{m}$; altura del manto 26-56 $\mu \mathrm{m}$; areolas en el centro 4-8 en $10 \mu \mathrm{m}$; en el manto 5-61/2 en $10 \mu \mathrm{m}$.

Referencias: Hasle \& Lange (1992), Sunesen (2007).

Distribución para Argentina: Coscinodiscus wailesii es una especie de aguas cálidas a templadas según Hasle \& Syvertsen (1996), cosmopolita según Fryxell \& Hasle (2004) y ha sido hallada en aguas de la plataforma bonaerense (Estación EPEA, 38 $28^{\prime} \mathrm{S}-57^{\circ} 41^{\prime} \mathrm{W}$ ) por Negri et al. (2004) y $\left(37^{\circ} 33^{\prime} \mathrm{S}-56^{\circ} 25^{\prime} \mathrm{W}\right)$ por Ferrario et al. (2008) y en aguas costeras del área norte de la Provincia de Buenos Aires por Sunesen (2007).

En el presente estudio, C. wailesii fue encontrada en las muestras de ambas estaciones de muestreo, escasa a abundante en invierno. La concentración máxima alcanzada por la especie en muestras cuantitativas fue del orden de $10^{3}$ cel L-1.

Asociación a eventos nocivos en otras áreas geográficas: Coscinodiscus wailesii es una de las especies productoras de mucílago citadas en la literatura como nocivas para otros organismos marinos. Hacia finales de los 70s pescadores del área de Plymouth, Inglaterra, observaron que sus redes se obstruían con un material gelatinoso espeso. La composición química de ese material resultó coincidente con la composición del mucílago producido por $C$. wailesii, importante componente del fitoplancton de dicha área a partir de 1977 (Fryxell \& Hasle 2004).

Nagai et al. (1995) señalaron a esta especie como una de las que causa mayor daño al cultivo de nori (Porphyra) 

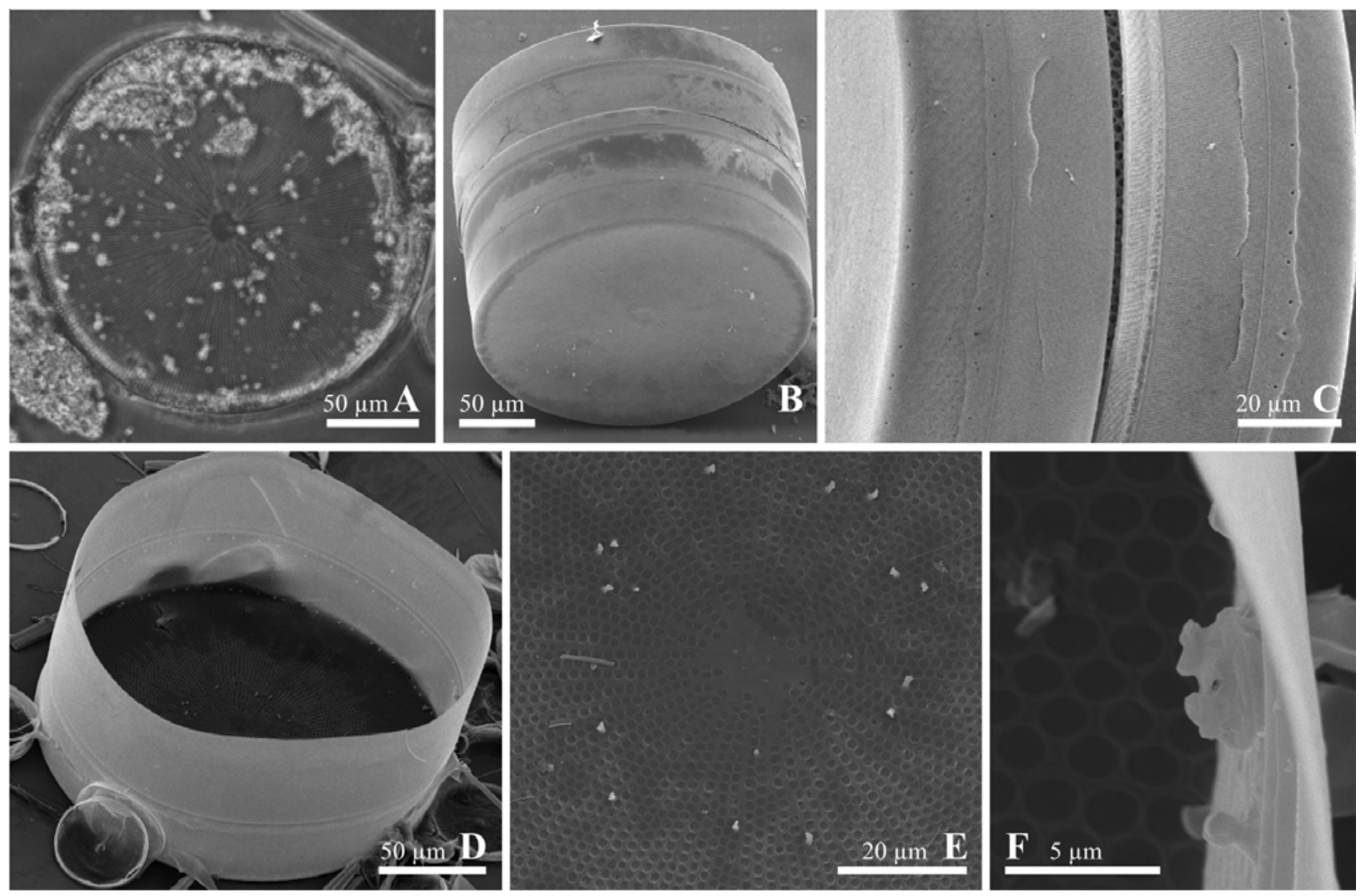

Figura 12

Coscinodiscus wailesii. A, MO. B-F, MEB. A. Célula en vista valvar. B. Frústulo inclinado, cilíndrico. C. Frústulo en vista cingular. D. Teca inclinada en vista interna. E. Parte central de la valva mostrando área hialina y procesos labiados pedicelados. F. Detalle del margen de la valva mostrando un proceso macrolabiado entre dos microlabiados

Coscinodiscus wailesii. A, LM. B-F, SEM. A. Cell in valvar view. B. Frustule tilted, cylindrical. C. Frustule in girdle view. D. Tilted theca in internal view. E. Central part of the valve showing a hyaline area and microlabiate, pedicelate processes. F. Detail of the valve margin showing a macrolabiate process between two microlabiate processes
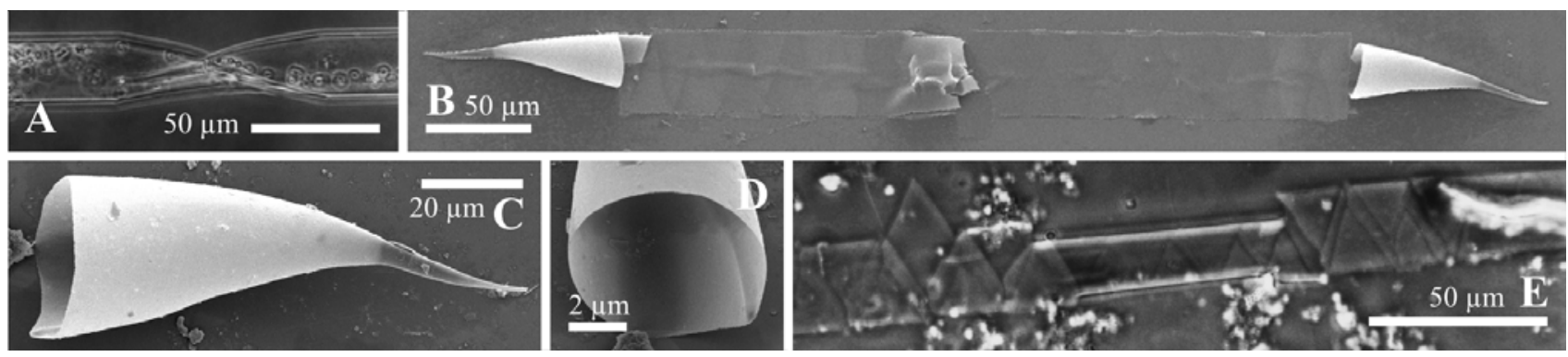

Figura 13

Pseudosolenia calcar-avis. A, E, MO. B-D, MEB. A. Parte de dos células unidas en cadena. B. Frústulo completo en vista lateral. C. Valva cónica con proceso curvado. D. Parte de la valva mostrando internamente la impronta del área contigua.

E. Cingulum con dos columnas de copulae en vista lateral

Pseudosolenia calcar-avis. A, E, LM. B-D, SEM. A. Part of two cells united in chain. B. Complete frustule in lateral view. C. Conical valve with curved process. D. Part of valve in internal view showing the impression of the contiguous area.

E. Cingulum with two columns of copulae in lateral view 
en aguas costeras del Mar de Japón por la remoción de nutrientes como el nitrógeno inorgánico en invierno y primavera. Asimismo, Fernandes et al. (2001) sugirieron la posibilidad de que las poblaciones de Coscinodiscus wailesii produzcan efectos negativos en la cadena trófica pelágica, ya que durante los períodos de floración de la especie en la Bahía de Paranaguá, Brasil, se observaron bruscas disminuciones de organismos del fitoplancton, zooplancton e ictioplancton.

\section{Familia Rhizosoleniaceae De Toni}

Pseudosolenia calcar-avis (Schultze) Sundström (Fig. 13 A-E)

Caracteres distintivos: Valva aguda a anchamente subcónica, asimétrica. Área contigua estrecha, hialina, sigmoidea. Ausencia de otarios y 'claspers'. Proceso en forma de garra. Estructura labiada grande, pedicelada, con los extremos espiralados (cornuportula). Segmentos (copulae) de la cintura ordenados en dos columnas dorsiventrales o en múltiples columnas. Areolas poroides redondeadas.

Parámetros morfométricos: longitud del frústulo 450-520 $\mu \mathrm{m}$; diámetro $30-40 \mu \mathrm{m}$.

Referencias: Sundström (1986), Sunesen \& Sar (2007a).

Distribución para Argentina: Pseudosolenia calcar-avis es una especie cosmopolita de aguas cálidas, ocasional en aguas templadas según Hasle \& Syvertsen (1996). Sin embargo, este taxon ha sido reportado en numerosas oportunidades para aguas costeras y de la plataforma del Mar Argentino hasta la Provincia de Chubut (ver Ferrario \& Galván 1989, bajo el nombre de Rhizosolenia calcaravis). Recientemente, Sunesen \& Sar (2007a) la hallaron en aguas costeras del área norte de la Provincia de Buenos Aires.

En el presente estudio, P. calcar-avis fue encontrada en ambas estaciones de muestreo, escasa en otoño e invierno.

Asociación a eventos nocivos en otras áreas geográficas: Pseudosolenia calcar-avis fue mencionada por Koray (2004) como causante de mortalidades masivas de organismos acuáticos, debido a las condiciones de hiperoxia y anoxia generadas por sus floraciones en zonas eutróficas de las costas de Turquía.

\section{Rhizosolenia setigera Brightwell f. setigera (Fig. 14 A-C)}

Caracteres distintivos: Valva cónica alargada con proceso muy largo en forma de aguja gradualmente atenuado hacia el extremo distal. Ausencia de otarios. Impresión del proceso en el frústulo adyacente ubicada en más de un segmento de la cintura. Segmentos (copulae) de la cintura en dos columnas dorsiventrales.

Parámetros morfométricos: longitud del frústulo 240-360 $\mu \mathrm{m}$; diámetro 8-12 $\mu \mathrm{m}$.
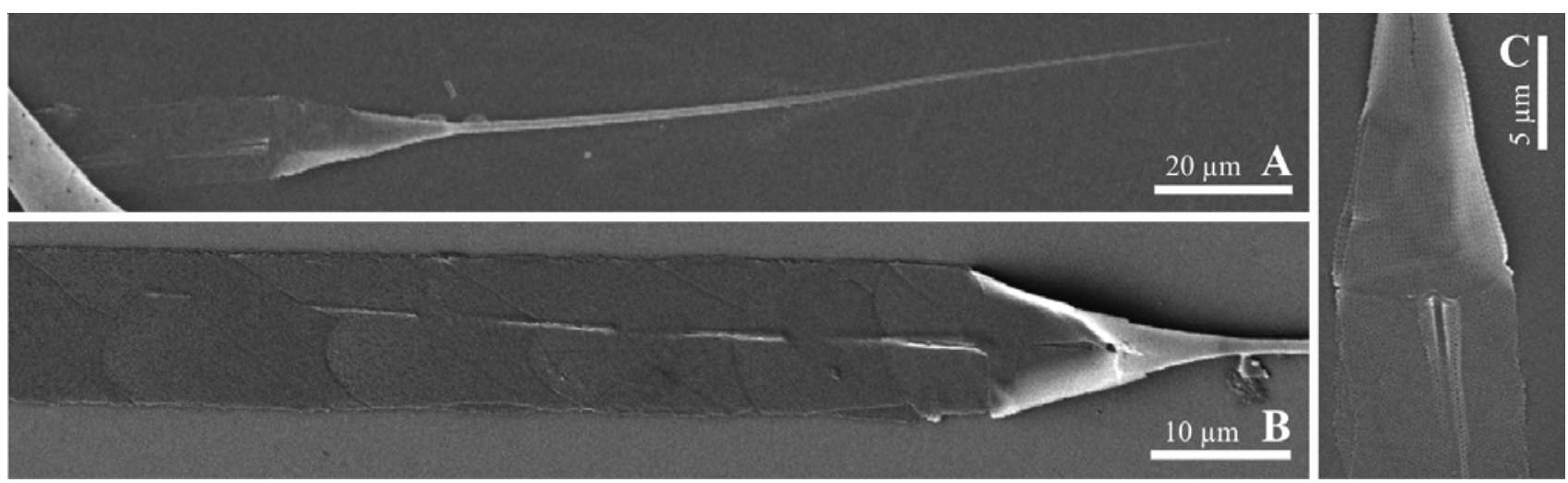

Figura 14

Rhizosolenia setigera f. setigera. MEB. A. Valva cónica con proceso largo en forma de aguja. B. Parte de un frústulo en vista dorsal mostrando la impresión del proceso de la valva adyacente. C. Parte de una teca en vista ventral mostrando los 'claspers'

Rhizosolenia setigera f. setigera. SEM. A. Conical valve with a needle-shaped process. B. Part of a frustule in dorsal view showing the impression of the adjacent valve process.

C. Part of a theca in ventral view showing the 'claspers' 

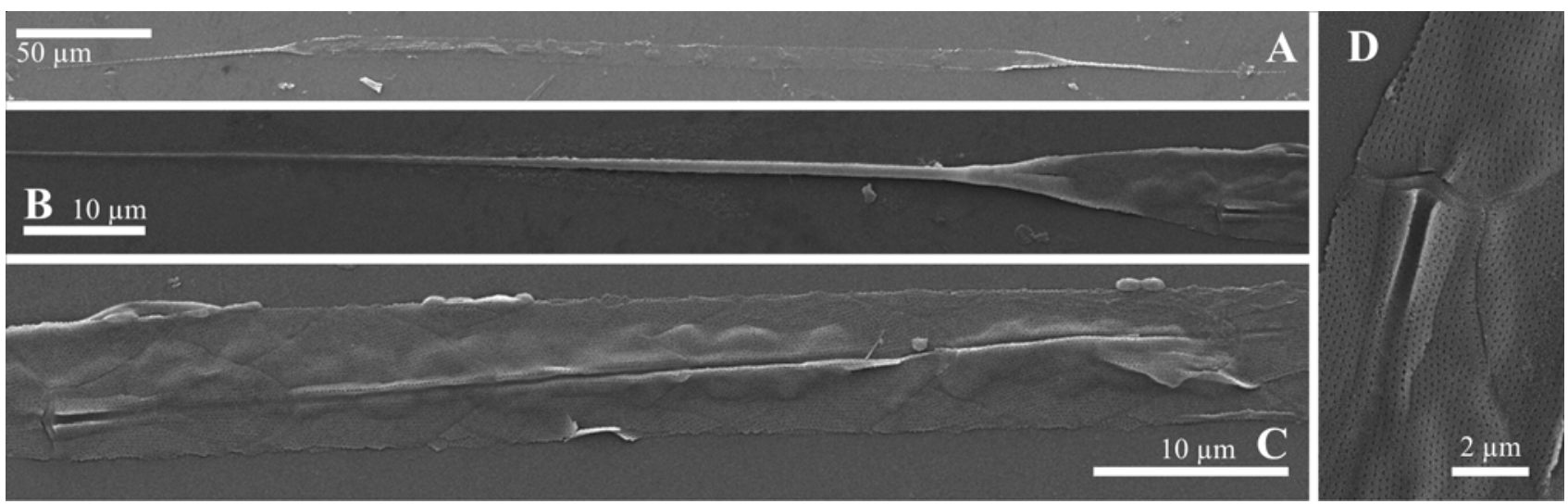

Figura 15

Rhizosolenia setigera f. pungens. MEB. A. Frústulo completo en vista lateral. B. Valva con parte del cingulum en vista ventral mostrando los ‘claspers'. C. Cingulum en vista ventral mostrando la impresión del proceso de la valva adyacente. D. Parte de una teca en vista ventral mostrando los 'claspers'

Rhizosolenia setigera f. pungens. SEM. A. Complete frustule in lateral view. B. Ventral view of a valve with part of the cingulum showing the 'claspers'. C. Ventral view of the cingulum with the impression to the adjacent valve process.

D. Part of a theca in ventral view showing the 'claspers'

Referencias: Sundström (1986), Sunesen \& Sar (2007a).

Distribución para Argentina en otras áreas geográficas: Rhizosolenia setigera f. setigera es un taxon cosmopolita, probablemente ausente en áreas polares según Hasle \& Syvertsen (1996). Esta forma ha sido reportada en varios trabajos para aguas neríticas y oceánicas en distintos puntos del Mar Argentino (ver Vouilloud 2003). Recientemente, Sunesen \& Sar (2007a) la hallaron en aguas costeras del área norte de la Provincia de Buenos Aires.

En el presente estudio, $R$. setigera f. setigera fue encontrada en ambas estaciones de muestreo, escasa a dominante en verano, otoño e invierno. La concentración máxima alcanzada por la especie en las muestras cuantitativas fue de $1,1 \cdot 10^{4}$ cél $\mathrm{L}^{-1}$.

Asociación a eventos nocivos en otras áreas geográficas: Rhizosolenia setigera ha sido reportada como productora de floraciones nocivas no tóxicas en la costa oeste de Estados Unidos (Horner et al. 1997) que pueden provocar mortandad de peces e invertebrados debido al agotamiento del oxígeno o afectar la dinámica de la cadena trófica.

Rhizosolenia setigera f. pungens (Cleve-Euler) Brunel (Fig. 15 A-D)

Caracteres distintivos: Valva cónica alargada, asimétrica. Proceso muy largo, en forma de aguja con la porción proximal ensanchada hasta la parte media. Ausencia de otarios. Impresión del proceso en el frústulo adyacente ubicada en más de un segmento de la cintura. Segmentos (copulae) de la cintura en dos columnas dorsiventrales.

Parámetros morfométricos: longitud del frústulo 133-360 $\mu \mathrm{m}$; diámetro 8-20 $\mu \mathrm{m}$.

Referencias: Brunel 1962, p.66, pl. 4, figs. 5-6; Sunesen \& Sar 2007a, p. 634, figs. 35-47.

Distribución para Argentina: Rhizosolenia setigera f. pungens se desarrolla principalmente en aguas salobres según Hasle \& Syvertsen (1996) y es de aguas templadas a subtropicales según Hernández-Becerril (1995). Este taxon ha sido reportado para aguas del Golfo San José (Ferrario et al. 1986) y del Golfo San Matías (Sar 1996), y para aguas costeras del norte de la Provincia de Buenos Aires (Sunesen \& Sar 2007a).

En el presente estudio, $R$. setigera $\mathrm{f}$. pungens fue encontrada en ambas estaciones de muestreo, escasa a abundante en otoño e invierno. La concentración máxima alcanzada por la especie en las muestras cuantitativas fue del orden de $10^{4}$ cél $\mathrm{L}^{-1}$.

Asociación a eventos nocivos en otras áreas geográficas: Rhizosolenia setigera f. pungens ha sido reportada como productora de eventos de mortandad de peces en cultivo en los fiordos del Sur de Chile (Cassis, com. pers. ${ }^{2}$ ).

\footnotetext{
${ }^{2}$ Cassis D. 2000. IV Jornadas Nacionales de Ciencias del Mar, Puerto Madryn, 11-15 de septiembre 2000.
} 


\section{Guinardia delicatula (Cleve) Hasle (Fig. 16 A-B)}

Caracteres distintivos: Colonias rectas. Células cilíndricas. Cintura compuesta por bandas no distinguibles al microscopio óptico. Valvas planas. Proceso marginal, con parte externa tubular delgada, oblicuamente dispuesta respecto del eje pervalvar.

Parámetros morfométricos: longitud del frústulo 40-60 $\mu \mathrm{m}$; diámetro $12-18 \mu \mathrm{m}$.

Referencias: Sundström (1986), Hasle \& Syvertsen (1996).

Distribución para Argentina: Guinardia delicatula es una especie característica de aguas templadas según Hasle \& Syvertsen (1996) y ha sido reportada en numerosas oportunidades para aguas costeras y de la plataforma del Mar Argentino hasta la Provincia de Santa Cruz (ver Ferrario \& Galván 1989, Vouilloud 2003) en muchos casos bajo el nombre de Rhizosolenia delicatula.

En el presente estudio, G. delicatula fue encontrada en ambas estaciones de muestreo, escasa en otoño.

Asociación a eventos nocivos en otras áreas geográficas: Guinardia delicatula ha sido reportada como productora de una floración en Noruega y causante de taponamiento de las redes de pescadores mediante un mucílago amarronado (Fryxell \& Hasle 2004).

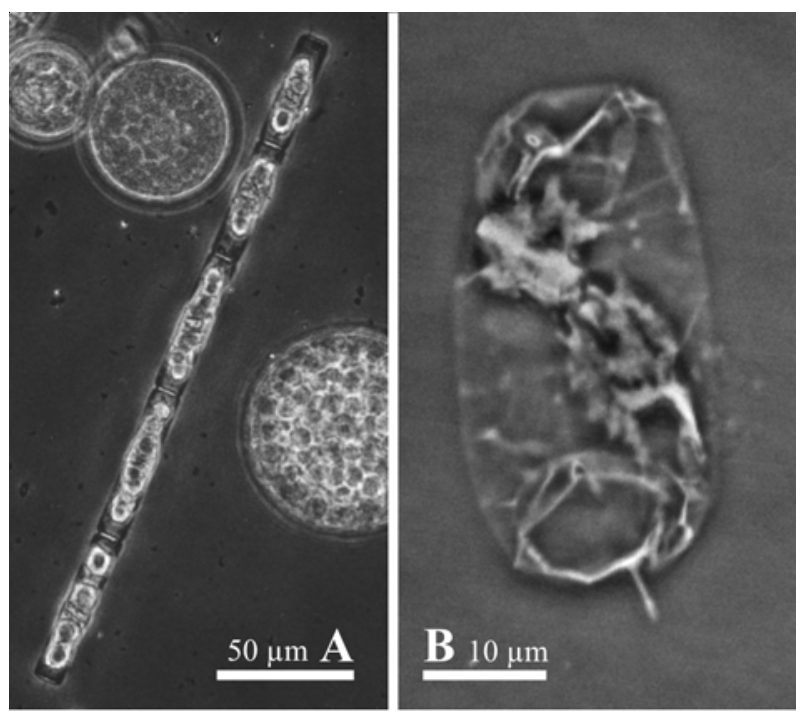

Figura 16

Guinardia delicatula. MO. A. Cadena recta. Note los procesos de ambas células terminales. B. Frústulo mostrando procesos

Guinardia delicatula. LM. A. Straight chain. Note processes on both terminal valves. B. Frustule showing processes

\section{Familia Hemiaulaceae Heiberg}

Cerataulina pelagica (Cleve) Hendey (Fig. 17 A-D)

Caracteres distintivos: Células en cadenas. Areolas ordenadas en estrías radiales que parten del proceso central o subcentral. Elevaciones bajas con ocelos costillados claviformes. Bandas de la cintura no visibles en muestras temporales.

Parámetros morfométricos: diámetro 14-36 $\mu \mathrm{m}$; eje pervalvar 30-80 $\mu \mathrm{m}$; areolas en el centro $32-40$ en 10 $\mu \mathrm{m}$; estrías 36-40 en $10 \mu \mathrm{m}$.

Referencias: Hasle \& Syvertsen (1980), Rivera et al. (2003), Sunesen \& Sar (2007b).
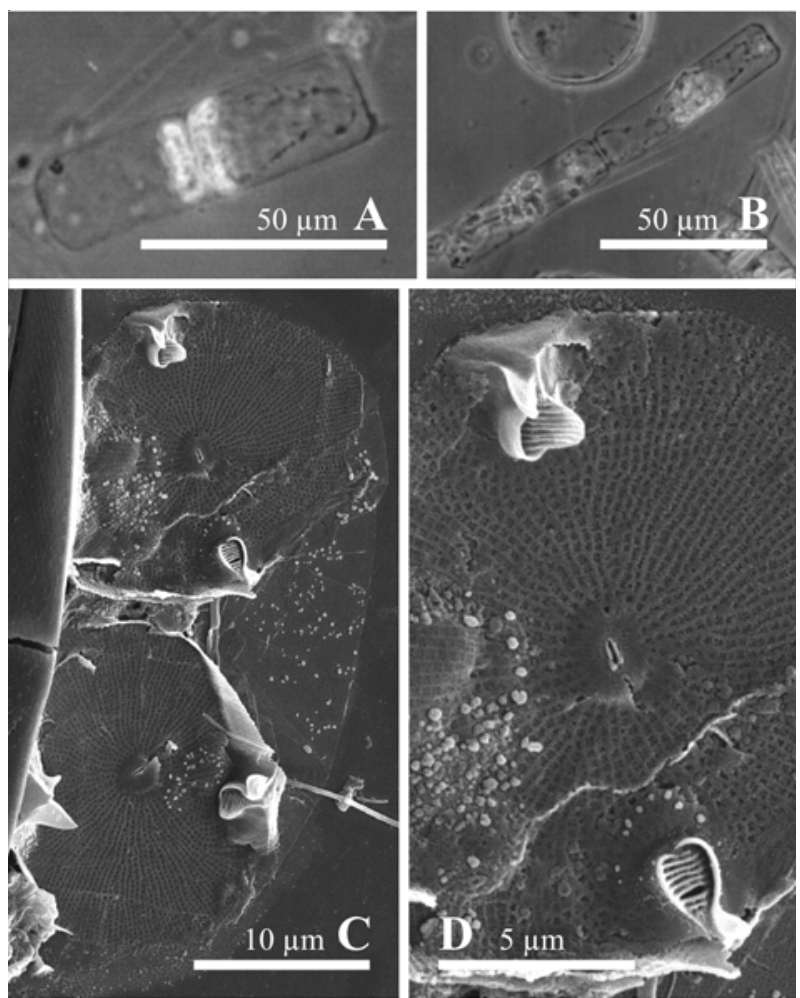

Figura 17

Cerataulina pelagica. A-B, MO. C-D, MEB. A. Célula solitaria en división. B. Cadena de dos células con abertura pequeña rectangular. $C$. Frústulo colapsado mostrando ambas valvas en vista externa. D. Detalle de una valva de la Fig. 17 C

Cerataulina pelagica. A-B, LM. C-D, SEM. A. Solitary cell in division. B. Chain of two cells with small rectangular aperture. C. Collapsed frustule with girdle showing both valves in external view.

D. Detail of one valve of Fig. $17 \mathrm{C}$ 

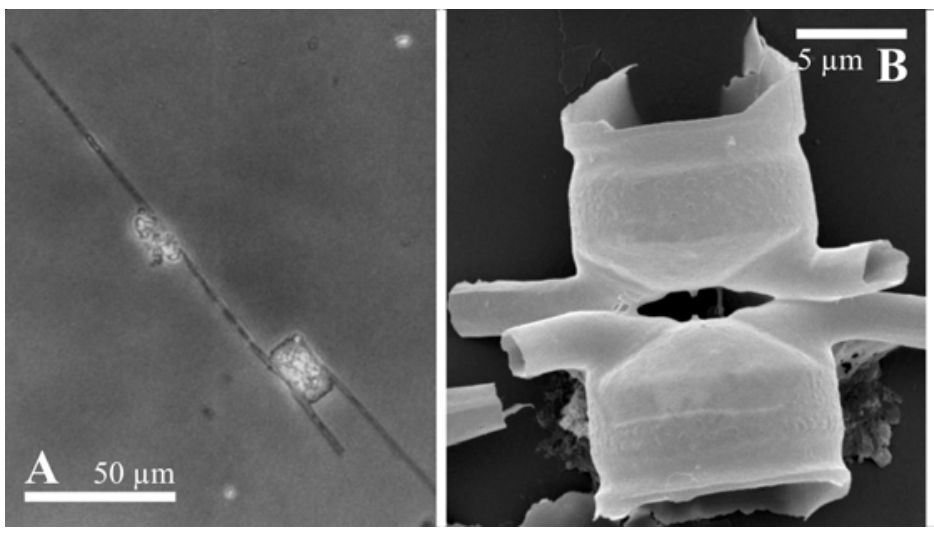

Figura 18
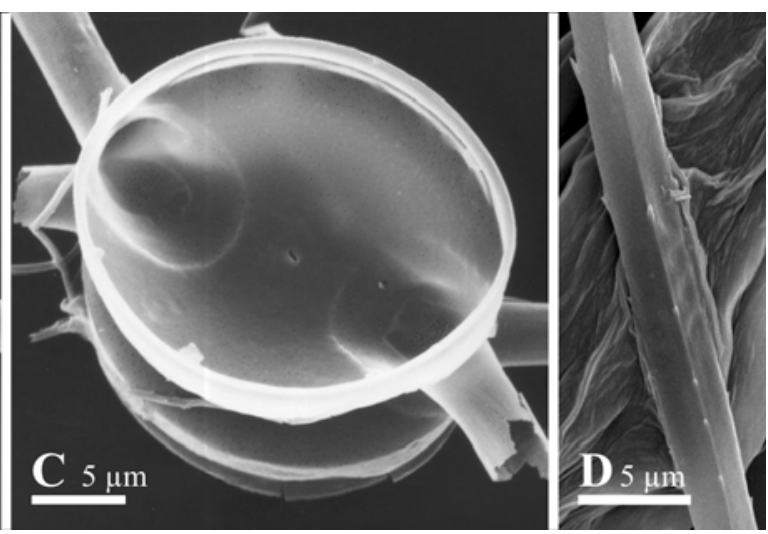

Chaetoceros danicus. A, MO. B-D, MEB. A. Célula solitaria. B. Tecas adyacentes en vista conectival. C. Vista valvar interna. D. Área distal de una seta

Chaetoceros danicus. A, LM. B-D, SEM. A. Solitary cell. B. Adjacent thecae in girdle view. C. Valve in internal view. D. Distal area of a seta

Distribución para Argentina: Cerataulina pelagica es una especie cosmopolita según Hasle \& Syvertsen (1996) y ha sido reportada en varias oportunidades para aguas del Mar Argentino (ver Ferrario \& Galván 1989, Vouilloud 2003). Recientemente Sunesen \& Sar (2007b) la han reportado para aguas costeras del área norte de la Provincia de Buenos Aires.

En el presente estudio, C. pelagica fue encontrada en ambas estaciones de muestreo, escasa en verano, otoño e invierno, sólo abundante en la muestra de Las Grutas del 25 de abril de 2006. La concentración alcanzada por la especie en esa fecha en la muestra cuantitativa fue de $4,5 \cdot 10^{3}$ cél L-1.

Asociación a eventos nocivos en otras áreas geográficas: Fryxell \& Hasle (2004) señalaron que en 1983 se produjo una floración de Cerataulina pelagica frente a las costas del nordeste de Nueva Zelanda en coincidencia con la muerte de moluscos y peces óseos, atribuida a anoxia y taponamiento de branquias.

\section{Familia Chaetoceraceae Ralf in Pritchard}

\section{Chaetoceros danicus Cleve (Fig. 18 A-D)}

Caracteres distintivos: Células solitarias o en cadenas cortas. Frústulos isovalvares. Setas largas, rectas, perpendiculares al eje pervalvar. Valvas con un proceso labiado central.

Parámetros morfométricos: eje apical 10-24 $\mu \mathrm{m}$; eje transapical 8-20 $\mu \mathrm{m}$.
Referencias: Koch \& Rivera (1984), Hernández-Becerril (1996), Jensen \& Moestrup (1998), Sunesen et al. (2008).

Distribución para Argentina: Chaetoceros danicus es una especie cosmopolita según Hernández-Becerril \& Flores Granados (1998) y ha sido reportada para aguas de plataforma frente a las costas de la provincia de Buenos Aires por Lange (1985) y para aguas costeras en el área norte de la Provincia de Buenos Aires por Sunesen et al. (2008).

En el área norte del Golfo San Matías durante el presente estudio, Ch. danicus fue encontrada en ambas estaciones de muestreo, escasa en verano y otoño.

Asociación a eventos nocivos en otras áreas geográficas: Chaetoceros danicus es una de las especies implicadas en eventos de mortandad masivas de peces en cultivo, debido a anoxia e hipercapnia generadas por el taponamiento de las branquias de los animales con el mucus que estos producen en respuesta al daño físico causado por las grandes setas espinosas (Horner et al. 1997).

\section{Chaetoceros debilis Cleve (Fig. 19 A-C)}

Caracteres distintivos: Colonias espiraladas. Células con un cloroplasto, unidas en cadenas por la fusión de las setas. Todas las setas curvadas hacia el lado externo de la colonia. Setas con una corta parte basal oblicua, que se fusionan ligeramente fuera del margen. Estatosporas con dos ondulaciones o gibas, sólo ausentes en las más pequeñas, con setas rudimentarias. 

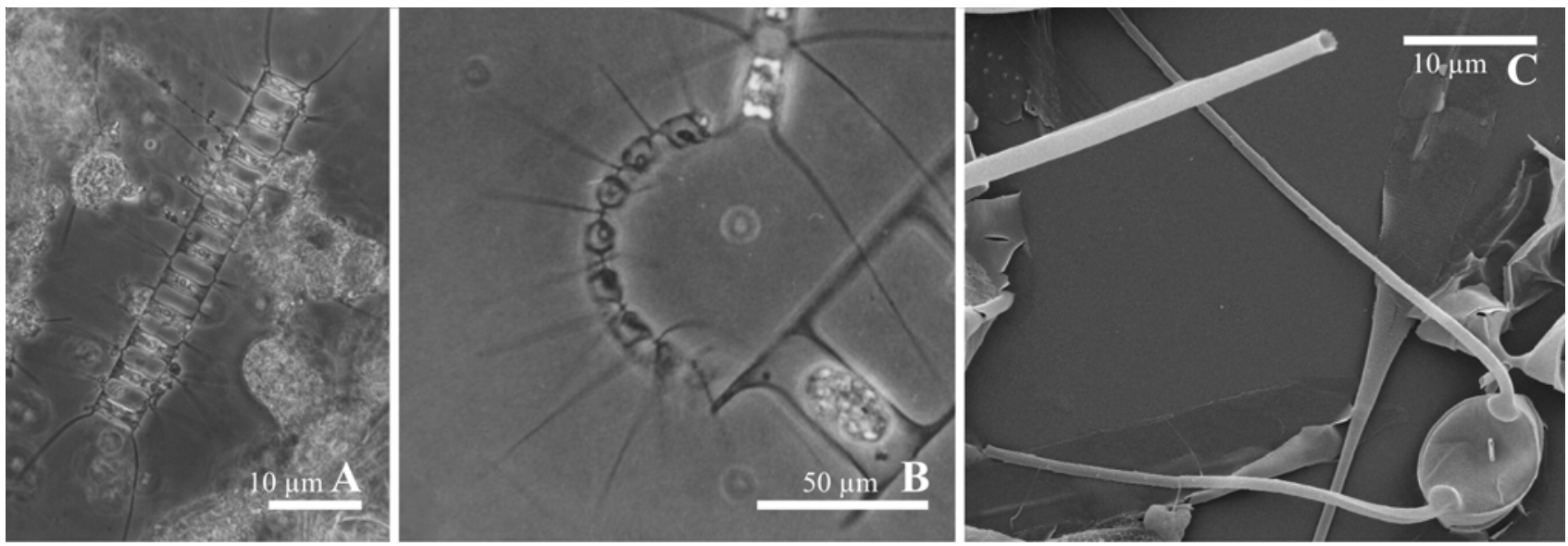

\section{Figura 19}

Chaetoceros debilis. A-B, MO. C, MEB. A. Colonia en vista conectival ancha. B. Colonia en vista conectival angosta. C. Valva de una célula terminal de la colonia

Chaetoceros debilis. A-B, LM. C, SEM. A. Chain in wide girdle view. B. Chain in narrow girdle view. C. Valve of a terminal cell of the colony
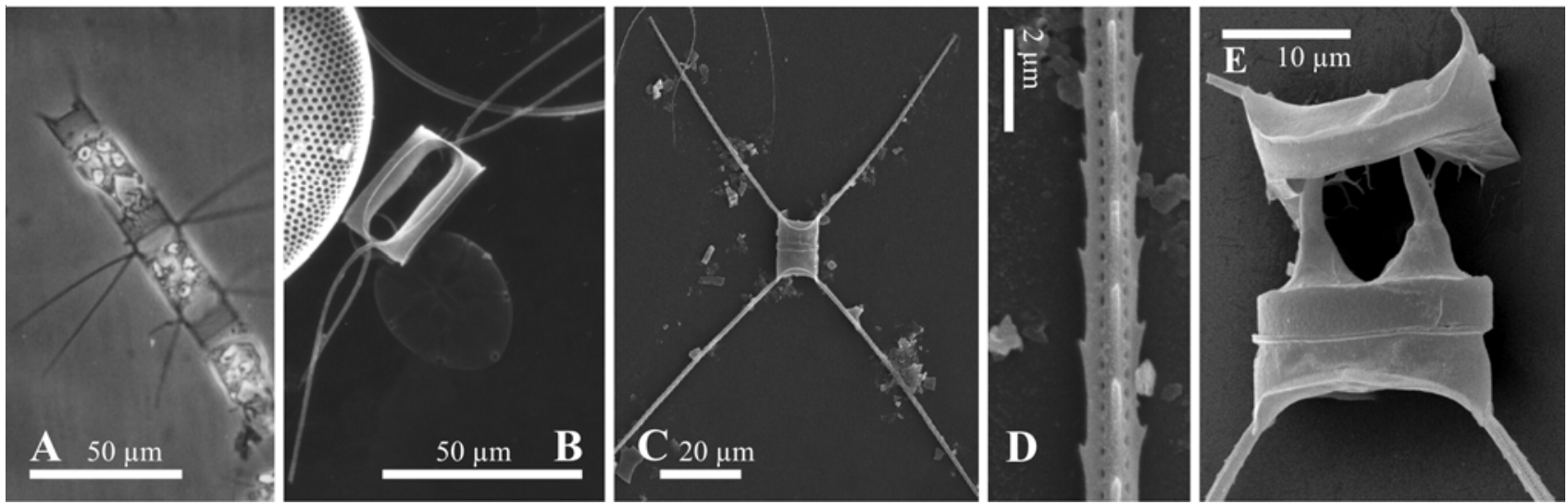

Figura 20

Chaetoceros lorenzianus. A, MO. B-E, MEB. A. Colonia con estatosporas. B. Par de valvas adyacentes de células vecinas en vista cingular. C. Célula solitaria. D. Parte distal de una seta. E. Célula solitaria con estatospora

Chaetoceros lorenzianus. A, LM. B-E, SEM. A. Chain with resting spores. B. Pair of sibling valves in girdle view.

C. Solitary cell. D. Distal part of a seta. E. Solitary cell with resting spore

Parámetros morfométricos: eje apical 9-15 $\mu \mathrm{m}$; eje transapical $8 \mu \mathrm{m}$.

Referencias: Hernández-Becerril (1996), Sunesen et al. (2008).

Distribución para Argentina: Chaetoceros debilis es una especie cosmopolita, principalmente en aguas frías según Hasle \& Syvertsen (1996) y ha sido reportada en varias ocasiones para aguas costeras y neríticas del Mar Argentino (ver Ferrario \& Galván 1989, Vouilloud 2003).
Recientemente, fue citada por Sunesen et al. (2008) para aguas costeras del área norte de la Provincia de Buenos Aires.

En el presente estudio, Ch. debilis fue encontrada en ambas estaciones de muestreo, escasa en verano, otoño e invierno.

Asociación a eventos nocivos en otras áreas geográficas: Chaetoceros debilis fue reportada como formadora de una floración asociada a mortandad de salmones en cultivo en las Islas Shetlands, Escocia (Smayda 2006). 


\section{Chaetoceros lorenzianus Grunow (Fig. 20 A-E)}

Caracteres distintivos: Células en cadenas rectas o solitarias. Cuatro a diez cloroplastos por célula. Los polos de las valvas adyacentes se tocan. Las setas se fusionan sólo en el punto de salida ligeramente fuera del margen de la colonia. Estatosporas con valvas disimilares, una con dos protuberancias cónicas ramificadas y la otra, lisa, con una o dos ondulaciones bajas.

Parámetros morfométricos: eje apical 15-22 $\mu \mathrm{m}$.

Referencias: Rines \& Hargraves (1988), Sunesen et al. (2008).

Distribución para Argentina: Chaetoceros lorenzianus es una especie de aguas cálidas según Hasle \& Syvertsen (1996) y de aguas tropicales y templadas según Cupp (1943). Esta especie cuenta con varias citas para aguas del Mar Argentino desde Buenos Aires hasta Chubut (Ferrario \& Galván 1989, Vouilloud 2003).

En el presente estudio, Ch. lorenzianus fue encontrada en ambas estaciones de muestreo, escasa a abundante en verano, otoño e invierno. La concentración máxima alcanzada por la especie en las muestras cuantitativas fue del orden de $10^{4}$ cél $\mathrm{L}^{-1}$.

Asociación a eventos nocivos en otras áreas geográficas: Chaetoceros lorenzianus fue reportada como productora de una gran mortandad de sardinas en el Golfo de Nicoya, en la costa Pacífico de Costa Rica a pesar de que no se observaron floraciones (Vargas-Montero \& Freer 2004).

Chaetoceros socialis Lauder (Fig. 21 A-B)

Caracteres distintivos: Células en cadenas curvas reunidas a su vez en colonias esféricas o irregulares embebidas en mucílago. Un cloroplasto por célula. Las valvas de células adyacentes no se tocan en los polos. Estatosporas de morfología y ornamentación muy variable.

Parámetros morfométricos: eje apical 6-17 (27) $\mu \mathrm{m}$; eje transapical 2,4-13 $\mu \mathrm{m}$.

Referencias: Evensen \& Hasle (1975), HernándezBecerril (1996), Jensen \& Moestrup (1998), Sunesen et al. (2008).

Distribución para Argentina: Chaetoceros socialis es una especie probablemente cosmopolita según Hasle \& Syvertsen (1996) y cosmopolita según HernándezBecerril \& Flores Granados (1998). Ella ha sido reportada por Hendey (1937) para aguas de Plataforma del Mar Argentino entre los $50^{\circ} 27^{\prime} \mathrm{S}$ y $50^{\circ} 53^{\prime} \mathrm{S}$, Frenguelli (1939b) para aguas del Golfo San Jorge, Ferrario en Kühnemann (1969) para la Ría de Puerto Deseado,

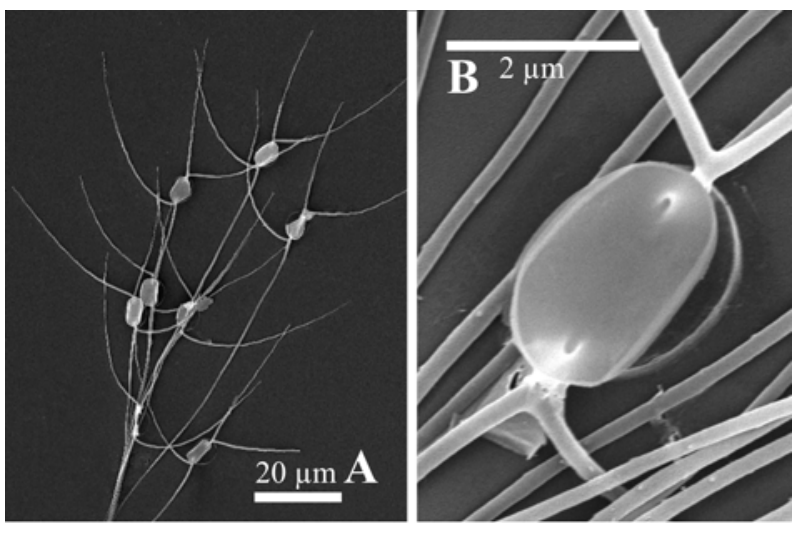

Figura 21

Chaetoceros socialis. MEB. A. Parte de una colonia.

B. Par de valvas adyacentes de células vecinas en vista valvar

Chaetoceros socialis. SEM. A. Part of a colony. B. Pair of sibling valves in valve view

Ferrario et al. (1986) aguas costeras de la Provincia de Chubut, Negri et al. (2004) para aguas de la plataforma frente a Mar del Plata y Sunesen et al. (2008) para aguas costeras del área norte de la Provincia de Buenos Aires.

En el presente estudio, Ch. socialis fue encontrada en ambas estaciones de muestreo, escasa en otoño y primavera.

Asociación a eventos nocivos en otras áreas geográficas: Chaetoceros socialis, como otras especies de diatomeas que forman colonias gelatinosas, fue reportada como productora de floraciones que causan taponamiento de branquias y anoxia en peces de cultivo y en organismos bentónicos (Smayda 2006). Clément \& Lembeye (1993) señalaron que esta especie desarrolla intensas y largas floraciones en el área de Chiloé central, Chile, y que las floraciones ocasionalmente afectaron el apetito de peces en jaulas.

\section{Conclusiones}

En lo referente a diatomeas toxígenas durante el transcurso del presente estudio a pesar de que Pseudo-nitzschia australis y $P$. pungens fueron abundantes en las muestras de invierno en las que ambas especies alcanzaron concentraciones del orden de $10^{3}$ cél $\mathrm{L}^{-1}$, no fueron detectados episodios de toxicidad humana. Según Reguera (2002) el rango de concentraciones celulares de microalgas planctónicas toxígenas del género Pseudonitzschia dentro del cual se manifiesta la presencia de toxinas en los bivalvos es del orden de $2 \cdot 10^{5}$ a $10^{6}$ cél L ${ }^{-1}$. Sin embargo, Negri et al. (2004) detectaron AD 
en muestras de fitoplancton, mejillones (Mytilus edulis) y anchoítas (Engraulis anchoita) concomitantemente con concentraciones de 1,3 a $2,810^{4}$ cél $\mathrm{L}^{-1}$ de Pseudonitzschia australis en una estación costera ubicada frente a Mar del Plata (38 $28^{\prime}$ S, $\left.57^{\circ} 41^{\prime} \mathrm{W}\right)$. Recientemente, Sar et al. (2006) aislaron cepas de Pseudo-nitzschia pungens provenientes de Las Grutas y Piedras Coloradas y analizaron los cultivos establecidos mediante Cromatografía Líquida de Alta Resolución (HPLC) obteniendo resultados negativos para AD. Otras dos especies toxígenas, Pseudo-nitzschia multiseries (Hasle) Hasle y $P$. pseudodelicatissima (Hasle) Hasle, previamente citadas para el área de estudio por Ferrario et al. (1999), no estuvieron presentes en el muestreo bajo análisis.

Ninguno de los 18 taxa hallados en el transcurso del presente estudio que fueron reportados como nocivos no toxígenos en otras áreas geográficas, ha provocado eventos nocivos en el área norte del Golfo San Matías.

Coscinodiscus wailesii es una especie cuya distribución se ha extendido a distintas áreas del planeta a partir de 1970 (Rince \& Paulmier 1986, Takano 1990, Hasle \& Lange 1992, Nagai et al. 1995, Edwards et al. 2001, Fernandes et al. 2001). En el Mar Argentino no hay reportes de $C$. wailesii anteriores a 1999 (Vouilloud 2003), pero a partir de esa fecha fue detectada por Negri et al. (2004), Sunesen (2007) y Ferrario et al. (2008) para aguas costeras de la Provincia de Buenos Aires. El actual es el primer reporte de $C$. wailesii para el Golfo San Matías donde devino uno de los componentes frecuentes del fitoplancton del área.

\section{Agradecimientos}

Los autores desean agradecer el apoyo logístico y técnico brindado por la Dra. Marcela Pascual, responsable del Criadero de Moluscos dependiente del Instituto de Biología Marina y Pesquera 'Alte. Storni', y la colaboración prestada por la Lic. Cecilia Castaños y el Sr. Pablo Sacco para la recolección de los materiales sobre los cuales se realizó el presente estudio. Asimismo expresan su reconocimiento a los dos anónimos revisores que contribuyeron a mejorar el manuscrito. Este trabajo fue financiado por el CONICET mediante el PIP 5312.

\section{Literatura citada}

Alcoverro T, E Conte \& L Mazzella. 2000. Production of mucilage by the Adriatic epipelic diatom Cylindrotheca closterium (Bacillariophyceae) under nutrient limitation. Journal of Phycology 36: 1087-1095.
Almandoz G, ME Ferrario, GA Ferreyra, IR Schloss, JL Esteves \& FE Paparazzo. 2007. The genus Pseudonitzschia (Bacillariophyceae) in continental shelf waters of Argentina (Southwestern Atlantic Ocean, $38-55^{\circ} \mathrm{S}$ ). Harmful Algae 6: 93-103.

Andersen RJ, SI Blackburn, FJR Taylor \& CR Tomas. 1995. Algal culture collections and toxic algal strains. En: Hallegraeff GM, DM Anderson \& AD Cembella (eds). Manual on harmful marine microalgae, pp. 489-531. IOC of UNESCO, Paris.

Anonymous. 1991. Domoic acid found in Oregon and Washington shellfish. Communicable Diseases Summary 40(24): 1-2. Oregon Health Division, Portland.

Bates SS. 2000. Domoic-acid-producing diatoms: another genus added!. Journal of Phycology 36: 978-983.

Bates SS, CJ Bird, ASW de Freitas, R Foxall, M Gilgan, LA Hanic, GR Johnson, AW Mcculloch, P Odense, R Pocklington, MA Quilliam, PG Sim, JC Smith, DV Subba Rao, ECD Tood, JA Walter \& JLC Wright. 1989. Pennate diatom Nitzschia pungens as the primary source of domoic acid, a toxin in shellfish from eastern Prince Edward Island, Canada. Canadian Journal of Fisheries and Aquatic Sciences 46: 1203-1215.

Brunel J. 1962. Le phytoplancton de la Baie des Chaleurs. Contributions du Ministère de la Chasse et des Pêcheries, Montreal 91: 1-365.

Buck KRL, L Uttal-Cooke, CH Pilskaln, DL Roelke, MC Villac, GA Fryxell, L Cifuentes \& FP Chavez. 1992. Autoecology of the diatom Pseudonitzschia australis, a domoic acid producer, from Monterrey Bay, California. Marine Ecology Progress Series 84: 293-302.

Cerino F, L Orsini, D Sarno, C Dell'Aversano, L Tartaglione \& A Zingone. 2004. The alternation of different morphotypes in the seasonal cycle of the toxic diatom Pseudo-nitzschia galaxiae. Harmful Algae 4: 33-48.

Clément A. 1994. Harmful blooms of Leptocylindrus minimus in Southern Chile. Harmful Algae News 8: 1.

Clément A \& G Lembeye. 1993. Phytoplankton monitoring programme in the fish farm region of the South of Chile. En: Smayda TJ \& Y Shimizu (eds). Toxic phytoplankton blooms in the sea, pp. 223-228. Elsevier, Amsterdam.

Cupp E. 1943. Marine plankton diatoms of the West coast of North America. Bulletin of the Scripps Institution of Oceanography of the University of California 5: 1-238.

Evensen DL \& GR Hasle. 1975. The morphology of some Chaetoceros (Bacillariophyceae) species as seen in the electron microscopes. Nova Hedwigia, Beiheft 53: 153-184.

Edwards M, AWG John, DG Johns \& PC Reid. 2001. Case history and persistence of the non-indigenous diatom Coscinodiscus wailesii in the north-east Atlantic. Journal of the Marine Biological Association of the United Kingdom 81: 207-211. 
Fernandes LF, L Zehnder-Alves \& JC Bassfeld. 2001. The recently established diatom Coscinodiscus wailesii (Coscinodiscales, Bacillariophyta) in Brazilian waters. I: Remarks on morphology and distribution. Phycological Research 49: 89-96.

Ferrario ME \& NM Galván. 1989. Catálogo de las diatomeas marinas citadas entre $\operatorname{los} 36^{\circ}$ y $\operatorname{los} 60^{\circ} \mathrm{S}$ con especial referencia al Mar Argentino. Publicación, Instituto Antártico Argentino 20: 1-327.

Ferrario ME \& EA Sar. 1988. Marine diatoms from Chubut (Argentina Republic) Centrales II - Thalassiosira. Revista Brasileira de Biologia 48: 421-429.

Ferrario ME, EA Sar \& RG Codina. 1986. Diatomeas marinas de la Provincia de Chubut (República Argentina). Centrales I. Darwiniana 27: 89-106.

Ferrario ME, EA Sar \& SE Sala. 1995. Metodología básica para el estudio del fitoplancton con especial referencia a las diatomeas. En: Alveal K, ME Ferrario, E Oliveira \& E Sar (eds), Manual de métodos ficológicos, pp. 1-23. Universidad de Concepción, Concepción.

Ferrario ME, EA Sar, C Castaños \& F Hinz. 1999. Potentially toxic species of the genus Pseudo-nitzschia in Argentinian coastal waters. Nova Hedwigia 68: 131-147.

Ferrario ME, EA Sar \& SE Sala. 2002. Diatomeas potencialmente toxígenas del Cono Sur Americano. En: Sar EA, ME Ferrario \& B Reguera (eds), Floraciones algales nocivas en el Cono Sur Americano, pp. 169-194. Instituto Español de Oceanografía, Madrid.

Ferrario ME, G Almandoz, S Licea \& I Garibotti. 2008. Species of Coscinodiscus (Bacillariophyta) from the Gulf of Mexico, Argentina and Antarctic waters: morphology and distribution. Nova Hedwigia, Beiheft 133: 187-216.

Frenguelli J. 1939a. XV Contribución al conocimiento de las diatomeas argentinas. Diatomeas del Golfo San Matías (Río Negro). Revista del Museo de La Plata. Nueva Serie 2, Botánica 10: 201-226.

Frenguelli J. 1939b. XIV Contribución al conocimiento de las diatomeas argentinas. Diatomeas de Rada Tilly, en el Golfo San Jorge (Chubut). Revista del Museo de La Plata. Nueva Serie 2, Botánica 9: 179-199.

Fritz L, MA Quilliam, JLCWright, AM Beale \& TM Work. 1992. An outbreak of domoic acid poisoning attributed to the pennate diatom Pseudo-nitzschia australis. Journal of Phycology 28: 439-442.

Fryxell GA \& GR Hasle. 1977. The genus Thalassiosira: some species with a modified ring of central strutted processes. En: Simonsen R (ed), Proceedings of the fourth symposium on recent and fossil marine diatoms. Nova Hedwigia, Beiheft 54: 67-98.

Fryxell GA \& GR Hasle. 2004. Taxonomy of harmful diatoms. En: Hallegraeff GM, DM Anderson \& AD Cembella (eds). Manual on harmful marine microalgae, pp. 465-509. IOC of UNESCO, Paris.
Fryxell GR \& MC Villac. 1999. Toxic and harmful marine diatoms. En: Stoemer EF \& JP Smol (eds). The diatoms: applications for the environmental and earth sciences, $p p$. 419-428. Cambridge University Press, Cambridge.

Garrison DL, SM Conrad, PPEilers \& EM Waldron. 1992. Confirmation of domoic acid production by Pseudonitzschia australis (Bacillariophyceae) cultures. Journal of Phycology 28: 604-607.

Gayoso AM. 1988. Variación estacional del fitoplancton de la zona más interna del estuario de bahía Blanca (Prov. Buenos Aires, Argentina). Gayana Botánica 45: 241-247.

Hallegraeff GM. 2004. Harmful algal blooms: A global overview. En: Hallegraeff GM, DM Anderson \& AD Cembella (eds). Manual on harmful marine microalgae, pp. 25-49. IOC of UNESCO, Paris.

Hargraves PE. 1990. Studies on marine plankton diatoms V. Morphology and distribution on Leptocylindrus minimus Gran. Nova Hedwigia, Beiheft 100: 47-60.

Hargraves PE \& L Maranda. 2002. Potentially toxic or harmful microalgae from the northeast coast. Northeastern Naturalist 9: 81-120.

Harris ASD, LK Medlin, J Lewis \& J Jones. 1995. Thalassiosira species (Bacillariophyceae) from a Scottish sea-loch. European Journal of Phycology 30: 117-131.

Hasle GR. 1965. Nitzschia and Fragilariopsis species studied in the light and electron microscopes. II. The group Pseudonitzschia. Det Norske Videnskaps-Akademi I Oslo I. Matematisk-Naturvidenskapelig. Klasse, Skrifter, Ny Serie 18: 1-45.

Hasle GR. 1976. The biogeography of some marine planktonic diatoms. Deep-Sea Research 23: 319-338.

Hasle GR. 2002. Are most of the domoic-acid producing species of the diatom genus Pseudo-nitzschia cosmopolites?. Harmful Algae 1: 137-146.

Hasle GR \& GA Fryxell. 1970. Diatoms: cleaning and mounting for light and electron microscopy. Transactions of the American Microscopic Society 89: 469-474.

Hasle GR \& GAFryxell. 1977. The genus Thalassiosira: some species with a linear areola array. Nova Hedwigia, Beiheft 54: $15-66$.

Hasle GR \& GA Fryxell. 1995. Taxonomy of diatoms. En: Hallegraeff GM, DM Anderson \& AD Cembella (eds). Manual of harmful marine microalgae, pp. 339-364. IOC of UNESCO, Paris.

Hasle GR \& CB Lange. 1992. Morphology and distribution of Coscinodiscus species from the Oslofjord, Norway, and the Skagerrak, North Atlantic. Diatom Research 7: 37-68.

Hasle GR \& EE Syvertsen. 1980. The diatom genus Cerataulina: Morphology and taxonomy. Bacillaria 3: 110118.

Hasle GR \& EE Syvertsen. 1996. Marine diatoms. En: Tomas CR (ed). Identifying marine phytoplankton, pp. 5-385. Academic Press, San Diego. 
Hasle GR, C Lange \& EE Syvertsen. 1996. A review of Pseudo-nitzschia, with special reference to the Skagerrak, North Atlantic, and adjacent waters. Helgoländer Meeresunters 50: 131-175.

Hendey NI. 1937. The plankton diatoms of the Southern Seas. Discovery Reports 16: 151-364.

Hernández-Becerril DU. 1995. Planktonic diatoms from the Gulf of California and coasts off Baja California: The genera Rhizosolenia, Proboscia, Pseudosolenia, and former Rhizosolenia species. Diatom Research 10: 251-267.

Hernández-Becerril DU. 1996. A morphological study of Chaetoceros species (Bacillariophyta) from the plankton of the Pacific Ocean of Mexico. Bulletin of the Natural History Museum of London, Botany Series 26: 1-73.

Hernández-Becerril DU \& C Flores Granados. 1998. Species of the diatom genus Chaetoceros (Bacillariophyceae) in the plankton from the Southern Gulf of Mexico. Botanica Marina 41: 505-519.

Horner RA, DL Garrison \& FG Plumley. 1997. Harmful algal blooms and red tide problems on the U.S. west coast. Limnology and Oceanography 42: 1076-1088.

Jahn R \& WH Kusber. 2005. Reinstatement of the genus Ceratoneis Ehrenberg and lectotypification of its type specimen: C. closterium Ehrenberg. Diatom Research 20: 295-304.

Jensen K \& Ø Moestrup. 1998. The genus Chaetoceros (Bacillariophyceae) in inner Danish coastal waters. Opera Botanica 133: 1-68.

Koch P \& P Rivera. 1984. Contribución al conocimiento de las diatomeas chilenas. III. El género Chaetoceros Ehr. (subgénero Phaeoceros Gran). Gayana Botánica 41: 61-84.

Koray T. 2004. Potentially toxic and harmful phytoplankton species along the coast of the Turkish Seas. En: Steindinger KA, JH Landsberg, CR Tomas \& GA Vargo (eds). Harmful Algae 2002, pp. 335-337. Florida Fish and Wildlife Conservation Commission, Florida Institute of Oceanography, and IOC of UNESCO, St. Petersburg, Florida.

Kotaki N, K Koike, M Yoshida, CV Thuoc, NT Minh Huyen, NC Hoy, Y Fukuyo \& M Kodama. 2000. Domoic acid production in Nitzschia sp. (Bacillariophyceae) isolated from a shrimp-culture pond in Do Son, Vietnam. Journal of Phycology 36: 1057-1060.

Kühnemann O. 1969. Vegetación marina de la Ría de Puerto Deseado. Contribución Científica del Centro de Investigaciones Biológicas Marinas (CIBIMA) 30: 1-123.

Lange C. 1985. Spatial and seasonal variations of the diatom assemblages off the Argentinian coast (South Western Atlantic). Oceanologica Acta 8: 361-370.

Lange C, RM Negri \& HR Benavides. 1983. Algunas especies del género Thalassiosira (Bacillariophyceae) del Mar Argentino. (Parte 1). Iheringia, Série Botânica 31: 9-30.
Lundholm N \& Ø Moestrup. 2000. Morphology of the marine diatom Nitzschia navis-varingica, sp. nov. (Bacillariophyceae), another producer of the neurotoxin domoic acid. Journal of Phycology 36: 1162-1174.

Lundholm N, J Skov, R Pocklington \& Ø Møstrup. 1994. Domoic acid, the toxic amino acid responsible for amnesic shellfish poisoning, now in Pseudo-nitzschia seriata (Bacillariophyceae) in Europe. Phycologia 33: 475-478.

Lundholm N, Ø Moestrup, GR Hasle \& K Hoef-Emden. 2003. A study of the Pseudo-nitzschia pseudodelicatissima/ cuspidata complex (Bacillariophyceae): what is $P$. pseudodelicatissima?. Journal of Phycology 39: 797-813.

Maranda L, R Wang, K Masuda \& Y Shimizu. 1990. Investigation of source of domoic acid en mussels. En: Graneli E, B Sundström, L Edler \& DM Anderson (eds). Toxic marine phytoplankton, pp. 300-304. Elsevier, New York.

Martin JL, K Haya, LE Burridge \& DJ Wildish. 1990. Nitzschia pseudodelicatissima - a source of domoic acid in the Bay of Fundy, eastern Canada. Marine Ecology Progress Series 67: 177-182.

Nagai S, Y Hori, T Manabe \& I Imai. 1995. Restoration of cell size by vegetative cell enlargement in Coscinodiscus wailesii (Bacillariophyceae). Phycologia 34: 533-535.

Negri RM \& D Inza. 1998. Some potentially toxic species of Pseudo-nitzschia in the Argentine Sea $\left(35^{\circ}-39^{\circ} \mathrm{S}\right)$. En: Reguera B, J Blanco, ML Fernández \& T Wyatt (eds). Harmful algae, pp. 84-85. Xunta de Galicia and IOC of UNESCO, Santiago de Compostela.

Negri RM, NG Montoya, JL Carreto, R Akselman \& D Inza. 2004. Pseudo-nitzschia australis, Mytilus edulis, Engraulis anchoita and domoic acid in the Argentine Sea. En: Steidinger KA, JH Landsberg, CR Tomas \& GA Vargo (eds). Harmful algae 2002, pp. 139-141. Florida Fish and Wildlife Conservation Commission, Florida Institute of Oceanography, and IOC of UNESCO, St. Petersburg, Florida.

Nikolaiev VA. 1993. The 'pore' apparatus of centric diatoms: A description of terms. Nova Hedwigia, Beiheft 106: 3342.

Prygiel J \& M Coste. 2000. Guide méthodologique pour la mise en oeuvre de 1'Indice Biologique Diatomées, NF T90354, 134 pp. Agence de 1'Eau Artois-Picardie \& CEMAGREF, Paris.

Reguera B. 2002. Establecimiento de un programa de seguimiento de microalgas tóxicas. En: Sar EA, ME Ferrario \& B Reguera (eds). Floraciones algales nocivas en el Cono Sur Americano, pp. 19-54. Instituto Español de Oceanografía, Madrid.

Rhodes L, D White, M Syhre \& M Atkinson. 1996. Pseudonitzschia species isolated from New Zealand coastal waters: domoic acid production in vitro and links with shellfish toxicity. En: Yasumoto T, Y Oshima \& Y Fukuyo (eds). 
Harmful and toxic algal blooms, pp. 155-158. IOC of UNESCO, Paris.

Rhodes L, C Scholin, I Garthwaite, A Haywood \& A Thomas. 1998. Domoic acid producing Pseudo-nitzschia species educed by whole cell DNA probe-based and immunochemical assays. En: Reguera B, J Blanco, ML Fernández \& T Wyatt (eds). Harmful algae, pp. 274-277. Xunta de Galicia and IOC of UNESCO, Santiago de Compostela.

Rince Y \& G Paulmier. 1986. Donées nouvelles sur la distribution de la diatomée marine Coscinodiscus wailesii Gran \& Angst (Bacillariophyceae). Phycologia 25: 73-79.

Rines JEB \& PE Hargraves. 1988. The Chaetoceros Ehrenberg (Bacillariophyceae) flora of Narragansett Bay, Rhode Island, USA. Bibliotheca Phycologica 79: 1-196.

Rivera P, S Avaria \& F Cruces. 2003. La Familia Hemiaulaceae (Bacillariophyceae) de las aguas marinas chilenas. Revista Chilena de Historia Natural 76: 651-664.

Rivera P, F Cruces \& A Clément. 2002. Leptocylindrus minimus Gran (Bacillariophyceae): morfología y distribución en Chile. Gayana Botánica 59: 7-11.

Ross R, EJ Cox, NI Karayeva, DG Mann, TBB Paddock, R Simonsen \& PA Sims. 1979. An amended terminology for the siliceous components of the diatom cell. Nova Hedwigia, Beiheft 64: 513-533.

Round FE, R Crawford \& DG Mann. 1990. The Diatoms. Morphology and Biology of the Genera. 747 pp. Cambridge University Press, London.

Sala SE, EA Sar \& ME Ferrario. 1998. Review of materials recorded as containing Amphora coffeaeformis (Agardh) Kützing in Argentina. Diatom Research 13: 323-336.

Sar EA. 1996. Flora diatomológica de Bahía San Antonio (Prov. de Río Negro, Argentina). O. Centrales I. Revista del Museo de La Plata. Nueva Serie 14, Botánica 106: 365-400.

Sar EA, D Andrinolo \& I Sunesen. 2006. Pseudo-nitzschia pungens (Grunow ex PT Cleve) Hasle var. pungens. Cultivo, morfología y análisis de toxinas. Boletín de la Sociedad Argentina de Botánica 41: 193-201.

Sar EA, ME Ferrario \& C Castaños. 1998. Authentication of the type material of Pseudo-nitzschia australis Frenguelli. Diatom Research 13: 183-185.

Sar EA, I Sunesen \& C Castaños. 2001. Marine diatoms from Buenos Aires coastal waters (República Argentina). I Thalassiosiraceae. Nova Hedwigia 73: 199-228.

Sar EA, I Sunesen \& A Lavigne. 2002. The diatom genus Thalassiosira: species from the northern San Matías Gulf (Río Negro, Argentina). Nova Hedwigia 74: 373-386.

Sastre AV, NH Santinelli, JL Esteves \& ME Ferrario. 2001. Aspectos ecológicos de especies de Pseudo-nitzschia en aguas costeras patagónicas (Argentina). En: Alveal K \& T Antezana (eds), Sustentabilidad de la biodiversidad, pp. 217-235. Universidad de Concepción, Concepción.
Scholin C, F Gulland, GJ Doucette, S Benson, M Busman, FP Chavez, J Cordaro, R DeLong, A De Vogelaere, J Harvey, M Haulena, K Lefebvre, $T$ Lipscomb, $S$. Loscutoff, LJ Lowenstine, R Marin, PE Miller, WA McLellan, PDR Moeller, CL Powell, T Rowles, $\mathbf{P}$ Silvagni, M Silver, T Spraker, V Trainer \& FM Van Dolah. 2000. Mortality of sea lions along the central California coast linked to a toxic diatom bloom. Nature 403: 80-83.

Smayda TJ. 2006. Harmful algal bloom communities in Scottish coastal aaters: Relationship to fish farming and regional comparisons - A Review. Scottish Executive Environment Group.[on-line].<http://www.scotland.gov.uk/ publications>

Smith JC, K Pauley, P Cormier, R Angus, P Odense, D O'Neil, MA Quilliam \& J Worms. 1991. Population dynamics and toxicity of various species of Dinophysis and Nitzschia from the southern Gulf of St. Lawrence. En: Gordon DC Jr. (ed), Proceedings of the Second Canadian Workshop on Harmful Marine Algae, p. 25. Canadian Technical Reports on Fisheries and Aquatic Sciences 1799: $1-25$.

Shimizu Y, S Gupta, K Masuda, L Maranda, CK Walker \& R Wang. 1989. Dinoflagellates and other microalgal toxins: chemistry and biochemistry. Pure and Applied Chemistry 61: 513-516.

Sunesen I. 2007. Diatomeas de ambientes costeros de la Provincia de Buenos Aires. Análisis taxonómico de los géneros que incluyen especies productoras de floraciones algales nocivas. Tesis Doctoral, Facultad de Ciencias Naturales y Museo, Universidad Nacional de La Plata, La Plata, Argentina, 392 pp.

Sunesen I \& EA Sar. 2004. Thalassiosira fryxelliae nov. spec. (Bacillariophyceae) from Argentinian coastal waters. Botanica Marina 47: 238-247.

Sunesen I \& EA Sar. 2007a. Marine diatoms from Buenos Aires coastal waters (Argentina). IV. Rhizosolenia s.str., Proboscia, Pseudosolenia, Neocalyptrella. Phycologia 46: 628-643.

Sunesen I \& EA Sar. 2007b. Diatomeas marinas de aguas costeras de la Provincia de Buenos Aires (Argentina). III. Géneros potencialmente nocivos Asterionellopsis, Cerataulina, Ceratoneis y Leptocylindrus. Revista Chilena de Historia Natural 80: 493-507.

Sunesen I, DU Hernández-Becerril \& EA Sar. 2008. Marine diatoms from Buenos Aires coastal waters (Argentina). V. Species of the genus Chaetoceros. Revista de Biología Marina y Oceanografía 43: 303-326.

Sundström BG. 1986. The marine diatom genus Rhizosolenia. Doctoral Dissertation. Lund University, Lund, Sweden. 117 pp.

Takano H. 1956. Harmful blooming of minute cells of Thalassiosira decipiens in coastal water in Tokyo Bay. Journal of Oceanographical Society of Japan 12: 63-67. 
Takano H. 1965. New and rare diatoms from Japanese marine waters. Bulletin Tokai Regional Fisheries Research Laboratory 42: 1-9.

Takano H. 1990. Diatoms. En: Fukuyo Y, H Takano, M Chiara \& K Matsouka (eds), Red tide organisms in Japan - An illustrated taxonomic guide, pp. 162-331. Uchida Rokakuho, Tokyo.

Todd ECD. 1990. Amnesic shellfish poisoning- a new seafood toxin syndrome. En: Graneli B, L Sundström, L Edler \& DM Anderson (eds), Toxic Marine Phytoplankton, pp. 504508. Elsevier Scientific Publishing, New York.

Vargas-Montero M \& E Freer. 2004. Proliferaciones algales de la diatomea toxigénica Pseudo-nitzschia (Bacillariophyceae) en el Golfo de Nicoya, Costa Rica. Revista de Biología Tropical 52, Suplemento 1: 127-132.
Villac MC, DL Roelke, FP Chavez, LA Cifuentes \& GA Fryxell. 1993. Pseudo-nitzschia australis Frenguelli and related species from the West coast of the U.S.A.: occurrence and domoic acid production. Journal of Shellfish Research 12: 457-465.

Vouilloud AA. 2003. Catálogo de diatomeas continentales y marinas de Argentina. Versión 1.0, 304 pp. Asociación Argentina de Ficología, La Plata. [CD-ROM].

Zavala-Camin LA \& N Yamanaka. 1980. Notas sobre um caso de mortandade de peixes, ocorrida em Itanhaém, São Paulo, Brasil. Boletim do Instituto Oceanografico 29: 377.

Zingone A \& T Wyatt. 2004. Harmful algal blooms: keys to the understanding of phytoplankton ecology. En: Robinson A, J McCarthy \& BJ Rothschild (eds). The Sea 13: 867926. President and Fellow of Harvard College, Harvard.

Recibido el 27 de junio de 2008 y aceptado el 14 de noviembre de 2008 